\title{
ESTUDIO DE LA PUBLICIDAD ACTIVA DE LA INFORMACIÓN PÚBLICA. ESPECIAL REFERENCIA A LA INFORMACIÓN AMBIENTAL Y A LA APLICACIÓN DE LA LEY 19/2013, DE 9 DE DICIEMBRE, DE TRANSPARENCIA, ACCESO A LA INFORMACIÓN PÚBLICA Y BUEN GOBIERNO
}

\author{
AitANA DE LA VARGA PASTOR \\ Profesora lectora de Derecho Administrativo acreditada a contratada doctora por \\ ANECA \\ Universitat Rovira i Virgili \\ aitana.delavarga@urv.cat
}

Recibido: 3 de abril de 2015 / Aceptado: 15 de abril de 2014

RESUMEN: Este artículo estudia de forma pormenorizada la regulación del acceso a la información ambiental en el Estado español, poniendo especial énfasis en la llamada difusión activa. Se detiene en el análisis de las obligaciones, los sujetos implicados y el contenido de dicha información, realizando un repaso histórico y un análisis de la normativa internacional, europea y española aplicable. Asimismo, y de forma paralela, analiza el acceso a la información pública y las novedades introducidas en el ordenamiento jurídico español a raíz de la incorporación de la Ley 19/2013, con especial referencia a la publicidad activa. El objetivo primordial del estudio es analizar la incidencia de esta ley general sobre transparencia en la ley especial que regula el acceso a la información ambiental, la Ley 27/2006, y si, en definitiva, comporta una ampliación, en cuanto a los sujetos obligados a la difusión de información en materia ambiental y en cuanto al contenido de la información que están obligados a difundir de forma activa, y en qué términos.

RESUM: Aquest article estudia de forma detallada la regulació de l'accés a la informació ambiental a l'Estat espanyol fent especial èmfasi en l'anomenada difusió activa. Es deté a l'anàlisi de les obligacions, els subjectes implicats i el contingut de 
l'esmentada informació, fent un repàs històric i anàlisi de la normativa internacional, europea i espanyola que li és aplicable. Així mateix, i de forma paral·lela, analitza l'accés a la informació pública i les novetats introduïdes a l'ordenament jurídic espanyol, arrel de la incorporació de la llei 19/2013, amb especial referència a la publicitat activa. L'objectiu primordial de l'estudi és analitzar la incidència d'aquesta llei general sobre transparència en la llei especial que regula l'accés a la informació ambiental, la 1lei 27/2006 i, si, en definitiva comporta una ampliació, en quant als subjectes obligats a la difusió de la informació en matèria ambiental i en quant al contingut de la informació que estan obligats a difondre de forma activa, i en quins termes.

ABSTRACT: This article examines in detail the regulation of access to environmental information in Spain with special emphasis on the called active dissemination. It studies the obligations, the subjects involved and the content of such information by a historical review. Indeed studies the international, the European and the Spanish legislation. Also, in parallel takes into account the new regulation in the Spanish legal system of access to public information through the law 19/2013, in particular the active advertising. The primary objective of the study is to analyze the impact of this general law of transparency in the special law that regulates access to environmental information, the law 27/2006. Ultimately entails an expansion in terms of the required to dissemination of information on environmental issues and in relation with the content of the information they are obliged to actively disseminate, and on what terms.

PALABRAS CLAVE: acceso a la información ambiental — información pública — publicidad activa - difusión activa.

PARAULES CLAU: accés a la informació ambiental — informació pública — publicitat activa - difusió activa.

KEY WORDS: access to environmental information — public information - active publicity — active dissemination. 
Sumario: I. Introducción. 1. El derecho de acceso a la información pública en el Estado español. 2. La evolución normativa en el ámbito del acceso a la información ambiental. 2.1. De la Conferencia de Estocolmo al Convenio de Aarhus. 2.2. De la Directiva 90/313/CEE a la Directiva 2003/4/CE. 2.3. De la Ley 38/1995, de 12 de diciembre, sobre el derecho de acceso a la información en materia de medio ambiente, a la Ley 27/2006, de 18 de julio, por la que se regulan los derechos de acceso a la información, de participación pública y de acceso a la justicia en materia de medio ambiente, y otras leyes sectoriales. II. La publicidad activa o difusión activa y el acceso a la información ambiental previa solicitud, dos modos de difusión de la información. III. Las obligaciones generales de difusión de la información ambiental. 1. El ámbito subjetivo: los sujetos sobre los que recaen las obligaciones generales en materia de información ambiental. 2. El ámbito objetivo: las obligaciones generales en materia de información ambiental. IV. La difusión activa de la información ambiental. 1. La difusión y puesta a disposición del público de la información ambiental: un elemento garantizado por la Ley 27/2006. 2. Los sujetos sobre los que recaen las obligaciones de difusión activa de la información ambiental y de la información pública. 3. Las obligaciones específicas en materia de difusión activa de información ambiental. 4. El contenido mínimo de la información ambiental objeto de difusión activa 5. La difusión de la información en caso de amenaza inminente para la salud humana o el medio ambiente. 6. Las consecuencias del incumplimiento de las obligaciones de difusión activa de la información. V. Conclusiones. VI. Bibliografía.

\section{INTRODUCCIÓN ${ }^{1}$}

La información que obra en manos de la Administración pública y que de motu proprio publica es un reflejo del principio de transparencia y forma parte del derecho de acceso a la información pública. Este derecho también comprende el derecho de los individuos y ciudadanos a solicitar información que obre en manos de las administraciones públicas. La normativa española aboga cada vez más por una Administración más transparente, lo que se ve reflejado en la legislación general y sectorial. El artículo 35 de la Ley 30/1992, de 26 de noviembre, de Régimen Jurídico de las Administraciones Públicas y del Procedimiento Administrativo Común (LRJ-PAC), en su redacción actual, reconoce el derecho de los ciudadanos, en sus relaciones con la Administración pública, al acceso a la información pública, archivos y registros. Su artículo 37 se remite a la Constitución, a la Ley de Transparencia, Acceso a la Información Pública y Buen Gobierno y demás leyes que resulten de aplicación. Por ese motivo, cabrá estudiar la Ley 19/2013, de 9 de diciembre, de Transparencia, Acceso a la Información Pública y Buen Gobierno, en adelante, Ley 19/2013, para conocer el alcance de dicho derecho. Sin embargo, hay ámbitos sectoriales que ya gozan de regulación propia, como es el

\footnotetext{
${ }^{1}$ Este trabajo se enmarca en el proyecto de investigación "Del desarrollo sostenible a la justicia ambiental: hacia una matriz conceptual para la gobernanza global", financiado por el Ministerio de Economía y Competitividad para el período 2014-2016 (DER2013-44009-P). También se ha realizado en el marco de la "Red Mercado y Medio Ambiente. Propuestas jurídicas para una economía verde" (ECOVER) (R/2014/040), dirigida por Francisco Javier Sanz Larruga y otorgada por Resolución de 8 de octubre de 2014 por la que se conceden ayudas para la consolidación y estructuración de unidades de investigación competitivas del sistema universitario de Galicia, convocadas mediante la Orden de 14 de mayo de 2014.
} 
caso, entre otros, del acceso a la información ambiental. La Ley 27/2006, de 18 de julio, por la que se regulan los derechos de acceso a la información, de participación pública y de acceso a la justicia en materia de medio ambiente (incorpora las directivas 2003/4/CE y 2003/35/CE), en adelante, Ley 27/2006, es fruto de la incorporación del Convenio de Aarhus a nuestro ordenamiento jurídico, el cual comprende el pilar del acceso a la información, junto con el de la participación pública y el del acceso a la justicia $^{2}$. Se configura como un derecho que abre las puertas al ejercicio del derecho de participación ${ }^{3}$ y también del derecho de acceso a la justicia. Asimismo, permitiendo este acceso a la información se consigue, o se permite conseguir, un logro aún mayor: elevar la concienciación pública ${ }^{4}$, en este caso, la ambiental y, por lo tanto, también la educación ambiental o ecológica ${ }^{5}$. En definitiva, vemos que su importancia radica sobre todo en el carácter instrumental que tiene y en el fundamento que supone para el

\footnotetext{
2 Sobre la participación y el acceso a la justicia en materia ambiental, véanse, entre otros, EZEIZABARRENA SÁENZ, X., "Participación y acceso a la justicia ambiental: el convenio de Aarhus de 1998", Revista Aranzadi de Derecho Ambiental, núm. 1, 2002, pp. 245-251; GARCÍA URETA, A., "Algunas cuestiones sobre la regulación del derecho de participación a la luz del Convenio de Aarhus de 1998", Revista Aranzadi de Derecho Ambiental, núm. 7, 2005, pp. 43-70; SALAZAR ORTUÑO, E., "E1 desarrollo del Convenio de Aarhus y la progresiva desaparición de obstáculos para el acceso a la justicia ambiental: reconocimiento en la jurisprudencia del Tribunal Supremo de la legitimación activa a las organizaciones no gubernamentales que trabajan a favor de la protección del ambiente", Revista Aranzadi de Derecho Ambiental, núm. 17, 2010, pp. 191-202, y del mismo autor, "Implicaciones del Convenio de Aarhus en la legislación sobre acceso a la justicia de los Estados: la Sentencia Trianel del Tribunal de Justicia de la Unión Europea de 12 de mayo de 2011, C-115/09", Revista Aranzadi de Derecho Ambiental, núm. 23, 2012, pp. 413-432.

${ }^{3}$ Hay unanimidad en considerar que el acceso a la información de que disponen las autoridades públicas es un requisito fundamental para la participación de los ciudadanos. LOZANO CUTANDA incide en que la medidas para garantizar el acceso y la difusión de la información ambiental constituyen, como es evidente, el presupuesto para una participación eficaz de los ciudadanos y de las ONG en la tutela ambiental; en ALONSO GARCÍA, E. y LOZANO CUTANDA, B., Diccionario de Derecho Ambiental, iustel, Madrid, 2005, p. 718.
}

${ }^{4}$ Según PLAZA MARTÍN: "[...] el acceso [...] y la difusión de la información contribuyen en palabras de la Comisión a una mayor conciencia en materia de medio ambiente", en PLAZA MARTín, C., Derecho Ambiental de la Unión Europea, Tirant lo Blanch, Valencia, 2005, p. 329. Por otro lado, existen autores que entienden como objetivos del derecho de acceso a la información, en primer lugar, la concienciación del público sobre cuestiones de interés general, con la consiguiente mejora en la preservación y realización del interés común, y, en segundo lugar, el presupuesto de la acción: una condición indispensable para la formación de la voluntad democrática y de la existencia de una opinión pública libre y para el ejercicio de los derechos de participación; en RAZQUIN LIZARRAGA, J.A. y RUIZ DE APODACA ESPINOSA, A., Información, participación y justicia en materia de medio ambiente, comentario sistemático a la Ley 27/2006, de 18 de julio, Thomson Aranzadi, Navarra, 2007, p. 167.

${ }^{5}$ El artículo 3.3 del Convenio de Aarhus establece que el acceso a la información ambiental favorece la educación ecológica del público, al que ha de concienciarse respecto de los problemas ambientales. También la Ley 27/2006 destaca en la exposición de motivos el papel esencial que desempeña el acceso a la información ambiental en la concienciación y educación ambiental de la sociedad, acceso que constituye un instrumento indispensable para poder intervenir con conocimiento de causa en los asuntos públicos. 
ejercicio de otros derechos, en este caso con la finalidad última de promover la efectiva protección del medio ambiente.

Con la Ley 27/2006 el derecho de acceso a la información pública, especialmente en materia medioambiental, se vio ampliado en relación con lo que preveía entonces la LRJ-PAC, lo que supuso un avance en estos derechos. La Ley 19/2013 pretende también ampliar este derecho de acceso a la información pública, en este caso en términos generales, de dos formas: por acción propia de las administraciones públicas a través de la llamada publicidad activa; y, por demanda del individuo de información concreta respecto a todos los ámbitos. Es de nuestro interés analizar y estudiar el encaje de ambas normativas y los efectos que la aplicación de la Ley 19/2013 va a tener en la Ley 27/2006, especialmente en lo que concierne a la publicidad activa tanto en relación con los sujetos obligados a dicha publicidad como con el contenido de esta.

\section{El derecho de acceso a la información pública en el Estado español}

El derecho de acceso a la información pública no se prevé tan solo en el campo ambiental, aunque es uno de los ámbitos en los que tiene más relevancia y más ha evolucionado. Es uno de los principios básicos de un Estado democrático de derecho y cumple tres funciones fundamentales y complementarias: 1) satisfacer el interés individual de los titulares del derecho a la información; 2) mejorar la dimensión objetiva, ya que repercute en el funcionamiento de la Administración al aumentar la transparencia; y 3) defender derechos e intereses legítimos, con carácter instrumental, de la información ${ }^{6}$. Su importancia radica también en el papel que asume de complementar la garantía jurisdiccional de control pleno de la actuación administrativa ${ }^{7}$. El principio de transparencia ${ }^{8}$, actualmente imperante, no se ha visto reflejado siempre en la historia de la Administración española, ya que en la época preconstitucional

\footnotetext{
${ }^{6}$ Así lo establece SÁNCHEZ MORÓN, M., Derecho Administrativo, parte general, $10^{\text {a }}$ edición, Tecnos, Madrid, 2014, pp. 464-474.

${ }^{7}$ En palabras de MESTRE DELGADO, el derecho de la información (concretada en el derecho de acceso a los archivos y registros) sirve "para completar la garantía jurisdiccional del control pleno de la actuación administrativa, fomentando la significación del principio participativo, consustancial con el principio democrático", en MESTRE DELGADO, J.F., El derecho de acceso a archivos y registros administrativos (Análisis del articulo 105.b) de la Constitución), Civitas, Madrid, 1993.

${ }^{8}$ Sobre este principio, véanse, entre otros, BLANES CLIMENT, M.Á., La transparencia informativa de las Administraciones públicas. El derecho de las personas a saber y la obligación de difundir información pública de forma activa, Aranzadi, Cizur Menor, 2014, pp. 64-93. Habla de la cultura de la transparencia o incluso del derecho a la transparencia, que forma parte de la tercera generación de
} 
predominaba el secretismo, la opacidad y la falta de transparencia como norma general ${ }^{9}$. La Constitución española de 1978 (CE) provocó un giro de 180 grados también en este ámbito, ya que con el establecimiento de principios democráticos se reconocerían expresamente los derechos de información, participación y justicia.

Centrándonos en el derecho a la información en el Estado español, el artículo 20 CE fija como derechos fundamentales la libertad de expresión y comunicación; el apartado primero letra $\mathrm{d}$, en concreto, el derecho a comunicar o recibir libremente información veraz por cualquier medio de difusión; y el artículo $23 \mathrm{CE}$, el derecho a participar en los asuntos públicos. El título IV CE, "sobre el gobierno y la administración”, refleja el principio de transparencia administrativa. El marco constitucional reconoce derechos a los ciudadanos e implanta la transparencia como elemento indispensable para la democracia ${ }^{10}$. El artículo105.b CE incide directamente en el acceso de los ciudadanos a los archivos y registros administrativos, pero mantiene el secreto administrativo en algunos ámbitos como la seguridad y defensa del Estado, la averiguación de los delitos y la intimidad de las personas ${ }^{11}$. Este artículo reconoce expresamente el derecho de los ciudadanos a acceder a la información que esté en poder de las administraciones públicas. ${ }^{12}$ En cuanto a la ubicación del citado artículo en el texto constitucional, José

derechos del hombre y engloba, a su vez, el derecho a saber: los ciudadanos tienen el derecho a saber qué ocurre en el interior de los poderes públicos que están a su servicio; el derecho a controlar la legalidad y la oportunidad de las decisiones; y el derecho a ser actores y no tan solo espectadores de la vida política, p. 67; GARCÍA MACHO, R. (ed.), Derecho administrativo de la información y administración transparente, Marcial Pons, Madrid, 2010. En relación con el principio, cabe hacer especial referencia a SOMMERMANN, K.P., "La exigencia de una Administración transparente en la perspectiva de los principios de democracia del Estado de derecho"; en GARCÍA MACHO, R. (ed.), Derecho administrativo .., cit., pp. 11-25, donde se concluye que "la transparencia administrativa es un elemento esencial en la estrategia de restablecer la confianza en el sistema democrático y de salvaguardar el Estado de Derecho en una realidad siempre más compleja”, p. 25; GUICHOT REINA, E. (coord.), Transparencia, acceso a la información pública y buen gobierno. Estudio de la Ley 19/2013, de 9 de diciembre, Tecnos, Madrid, 2014.

${ }^{9}$ El artículo 1 de la Ley de Secretos Oficiales, de 5 de abril de 1968, modificada por la Ley de 7 de octubre de 1978 y la Ley de Funcionarios, así lo plasmaba. Pero no solo en esta época, sino también mucho antes, desde el antiguo régimen, ya que el secreto administrativo siempre ha sido una herramienta de y del poder. Sin embargo, a partir de la década de 1970 el secretismo administrativo se comenzó a revelar como una medida ineficaz para la propia Administración. Para mayor abundamiento en la evolución del secreto a la transparencia en la Administración pública española, véase JIMÉNEZ PLAZA, M.I., El Derecho de acceso a la información municipal, iustel, Madrid, 2006, pp. 20-27; y MESTRE DELGADO, El derecho..., cit., entre otros.

${ }^{10}$ Junto a este artículo $20 \mathrm{CE}$ y también el artículo 23.2, sobre el derecho fundamental a la participación en asuntos públicos, cabe tener en cuenta los artículos 103, 105 y $106 \mathrm{CE}$.

${ }^{11}$ Para un análisis de este artículo, véase JIMÉNEZ PLAZA, El Derecho de acceso..., cit., pp. 30-48.

${ }^{12} \mathrm{Y}$, como señala JIMÉNEZ PLAZA, supuso el reconocimiento al máximo nivel normativo de un derecho general de todos los ciudadanos a informarse sobre la actuación de las administraciones públicas en el desempeño de sus funciones y, en consecuencia, también el reconocimiento de un deber general de 
Luís PIÑAR MAÑAS pone de manifiesto que "parece que prevalece la configuración, tanto del derecho de acceso como de la transparencia como principio de actuación de las Administraciones públicas"13. Emilio GUICHOT REINA considera "en lo sustantivo que el derecho a recibir información, habida cuenta de la importancia del flujo de la información que posee en exclusiva el poder público en la llamada sociedad de la información, hubiera constituido un anclaje suficiente para conectar libertad de información y derecho de acceso" ${ }^{\text {, }}$, por lo que aboga por una conexión entre el artículo 20.1.d y el artículo 105.b CE. Entiende no solo deseable sino también posible "una interpretación de la libertad de información del artículo 20.1.d en línea con el Derecho internacional y europeo y con su propia función en un Estado democrático y a la luz de su percepción social"15.

El artículo 105.b fue desarrollado por la LRJ-PAC ${ }^{16}$. De la versión vigente de esta ley debemos citar y destacar varios preceptos relacionados con la materia de estudio. A partir de la modificación de la Ley de 1999, el artículo 3.5 establece, como principios de actuación de las administraciones públicas en relación con los ciudadanos, los de transparencia y participación. Por su parte, el artículo 35 enumera los derechos de los

estas a conceder la información solicitada por aquellos, salvo que concurrieran algunas de las causas tasadas que excepcionan su ejercicio; JIMÉNEZ PLAZA, El Derecho de acceso..., cit., p. 33.

13 Tras un análisis del derecho de acceso a la información pública en términos generales, llega a la conclusión de que debería considerarse como un derecho fundamental. Se lamenta de que la Ley 19/2013 no lo haya considerado así por cuanto es una ley ordinaria y no orgánica, y, por lo tanto, el legislador ha optado por configurar el acceso a la información como manifestación del principio de transparencia, pero no como derecho fundamental. PIÑAR MAÑAS, J.L., "Transparencia y protección de datos. Una referencia a la Ley 19/2013, de 9 de diciembre, de transparencia, acceso a la información y buen gobierno", Piñar Mañas, J. L. (dir.), Transparencia, acceso a la información y protección de datos, ed. Reus, Madrid, 2014, p. 46.

${ }^{14}$ GUICHOT, E., "Transparencia: aspectos generales", Guichot Reina, E. (coord.), Transparencia, acceso a la información pública y buen gobierno. Estudio de la Ley 19/2013, de 9 de diciembre, Tecnos, Madrid, 2014, p. 46.

${ }^{15}$ Asimismo, advierte que el TC no hubiera podido pronunciarse en contra: "Ello hubiera sido compatible con dotar del rango de orgánicas a las disposiciones sobre el ámbito, el contenido del derecho y sus límites, y establecer un régimen diferenciado en función del sujeto obligado, por leyes ordinarias, para los mecanismos de publicidad activa, el procedimiento de ejercicio del derecho y las reclamaciones contra las inadmisiones o las denegaciones totales o parciales para los diferentes sujetos obligados"; en GUICHOT REINA, Transparencia..., cit., pp. 46 y 47. García Macho se lamenta también de que no haya una mayor conexión entre los tres artículos citados en beneficio de un buen funcionamiento de los principios democráticos e incluso del sistema democrático en su conjunto; GARCÍA MACHO, R., "El derecho a la información, la publicidad y transparencia en las relaciones entre la administración, el ciudadano y el público", García Macho, R. (ed.), Derecho administrativo de la información y administración transparente, Marcial Pons, Madrid, 2010, p. 42.

${ }^{16}$ Como bien advierte JIMÉNEZ PLAZA, vino a sentar formalmente las "bases del régimen jurídico de las Administraciones públicas", refiriéndose a las "bases" del artículo 149.1.18 CE, ya que el derecho de acceso no solo es ejercitable en el marco de un procedimiento administrativo, sino también al margen de este; en El Derecho de acceso..., cit., p. 49. 
ciudadanos en sus relaciones con las administraciones públicas, entre los que se reconocen el de conocer, en cualquier momento, el estado de la tramitación de los procedimientos en los que tengan la condición de interesados y obtener copias de documentos contenidos en ellos (a), así como el acceso a la información pública, los registros y archivos $(\mathrm{h})^{17}$. Anteriormente, el artículo 37 regulaba el acceso a estos archivos y registros y establecía en qué condiciones se podía acceder a ellos y cuándo se podía denegar el acceso, siendo la regulación establecida muy restrictiva, pero la Ley 19/2013 ha cambiado drásticamente su redacción y se limita a remitirse a la Constitución, a la Ley de Transparencia, Acceso a la Información Pública y Buen Gobierno y demás leyes que resulten de aplicación. Por otro lado, ya en el marco de las disposiciones generales sobre procedimientos administrativos, el artículo 86 regula el trámite de información pública. No obstante, no debemos confundir este trámite con el derecho de acceso a la información pública. La Ley reguladora de las Bases del Régimen Local también refleja estos principios, siendo pionera en ello ${ }^{18}$.

No debe pasar desapercibido que a día de hoy existe el Anteproyecto de Ley del Procedimiento Administrativo Común de las Administraciones Públicas que sustituirá a la actual LRJ-PAC. Dicho anteproyecto, que fue sometido a información pública el 16 de enero de 2015, contempla la cuestión de la transparencia ya no como principio general, sino incluido en el impulso del procedimiento (art. 98). Asimismo, el artículo 27 , dedicado a los derechos de las personas en sus relaciones con las administraciones públicas, remite expresamente a la Ley 19/2013 cuando prescribe que "las personas, en sus relaciones con las Administraciones públicas, tienen los siguientes derechos: d) al acceso a la información pública, archivos y registros, de acuerdo con lo previsto en Ley 19/2013, de 9 de diciembre, de transparencia, acceso a la información pública y buen gobierno y el resto del Ordenamiento Jurídico". Cabe apreciar que ya no se refiere a los ciudadanos sino a las personas. Por último, el capítulo II, “principios del procedimiento de elaboración de normas", incluye, entre los principios de buena regulación, que las administraciones públicas, en el ejercicio de la iniciativa legislativa y la potestad

\footnotetext{
${ }^{17}$ Con anterioridad a la modificación producida por la Ley 19/2013, el apartado h) de este artículo rezaba así: "[...] al acceso a los registros y archivos de las Administraciones públicas en los términos previstos en la constitución y en ésta u otras leyes".

${ }^{18}$ Concretamente, el capítulo IV, “información y participación ciudadana”, del título V, “disposiciones comunes de las entidades locales" (arts. 69 y ss.) de la Ley 7/1985, de 2 de abril, reguladora de las Bases del Régimen Local (LBRL). El artículo 69.1 reza así: "Las Corporaciones locales facilitarán la más amplia información sobre su actividad y la participación de todos los ciudadanos en la vida local". Para mayor abundamiento, véase JIMÉNEZ PLAZA, El Derecho de acceso..., cit., p. 63 y ss.
} 
reglamentaria, actúen de acuerdo con los principios de necesidad, eficacia, proporcionalidad, seguridad jurídica, transparencia y eficiencia. También exige que en la exposición de motivos o en el preámbulo, según se trate, respectivamente, de anteproyectos de ley o de proyectos de reglamento, quede suficientemente justificada la adecuación a dichos principios (art. 157).

\section{La evolución normativa en el ámbito del acceso a la información ambiental}

\subsection{De la Conferencia de Estocolmo al Convenio de Aarhus}

El derecho de acceso a la información ha evolucionado durante las últimas décadas impulsado por declaraciones y normativas internacionales, sobre todo en el ámbito concreto del medio ambiente ${ }^{19}$, debido, en gran medida, a su carácter instrumental, que permite la participación de los ciudadanos en los procesos de toma de decisiones, y a la importancia que esta materia está adquiriendo por la imperante necesidad de preservar el planeta. En el ámbito internacional, ya en 1972 el principio 19 de la Declaración de Estocolmo propugnó la indispensable labor educativa para lograr una opinión pública bien informada y el papel esencial de los medios de comunicación para la protección ambiental. Unos años más tarde, la Carta Mundial de la Naturaleza de 1982 expresó, entre otras, la idea de difusión de la información. En la Declaración sobre el Medio Ambiente y el Desarrollo de Río de Janeiro, de 1992, el principio 10 declaró los derechos de información, participación pública y acceso a la justicia ciudadana. En este principio se reconocieron de forma conjunta estos tres pilares conectados entre sí. En relación con el derecho de acceso a la información, el principio se refirió a él en los siguientes términos: "[...] toda persona deberá tener acceso adecuado a la información sobre medio ambiente". Este fue el primer paso firme a nivel internacional en este ámbito, que luego se vio reflejado en convenios internacionales donde estos derechos pasaron de ser soft law a ser vinculantes. La Cumbre de Johannesburgo de 2002 confirmó estos principios acordados en la Declaración de Johannesburgo sobre el Desarrollo Sostenible. El Convenio de Aarhus fue el resultado de este proceso, el texto internacional que regula de forma general y vinculante la información, la participación y

\footnotetext{
${ }^{19}$ Véase, entre otros, PIGRAU SOLÉ, A. (coord.), Acceso a la información, participación pública y acceso a la justicia en materia de medio ambiente: diez años del Convenio de Aarhus, Atelier, Barcelona, 2008.
} 
la justicia ambientales ${ }^{20}$. Al mismo tiempo, esta norma se configura como el punto de partida de la normativa europea e interna que adoptará su contenido en relación con los tres derechos, entre ellos, el de acceso a la información ambiental.

\subsection{De la Directiva 90/313/CEE a la Directiva 2003/4/CE}

En el ámbito de la Unión Europea, la Directiva 90/313/CEE del Consejo, de 7 de junio de 1990, sobre libertad de acceso a la información en materia de medio ambiente ${ }^{21}$, reguló por primera vez el libre acceso a la información ambiental en manos de los poderes públicos de forma general, con anterioridad al Convenio de Aarhus ${ }^{22}$, lo que inició un cambio en la actuación de las autoridades públicas en relación con el principio de transparencia ${ }^{23}$. No obstante, tras la aprobación de dicho Convenio y tras los resultados reflejados en el Informe de la Comisión elaborado en el año 2000, “Informe sobre la experiencia adquirida en la aplicación de la Directiva 90/313”, donde se analizó la aplicación de la Directiva ${ }^{24}$, se decidió sustituirla por una nueva, la Directiva 2003/4/CE del Parlamento y del Consejo, de 28 de enero de 2003, relativa al acceso del público a la información medioambiental ${ }^{25}$, que derogaría la anterior y cuya finalidad

\footnotetext{
20 Se trata de la Convención de la Comisión Económica de las Naciones Unidas para Europa (CEPE/ONU) sobre "El acceso a la información, la participación del público en la toma de decisiones y el acceso a la justicia en asuntos ambientales", adoptada en la Conferencia Ministerial "Medio Ambiente para Europa", celebrada en Aarhus, Dinamarca, el 25 de junio de 1998, y que entró en vigor el 30 de octubre de 2001. Fue firmada por 40 partes y ratificada por 39 de ellas, entre las que se encuentra la Unión Europea, que la firmó en 1998 y la aprobó mediante Decisión del Consejo 2005/370/CE, de 17 de febrero. España, aunque la firmó tempranamente, no la ratificó hasta el 29 de diciembre de 2004, entrando en vigor el 31 de marzo de 2005.
}

${ }^{21}$ DOCE L 151/1 de 15/6/1990. Sobre esta directiva, véase GARCÍA URETA, A., "Perspectivas sobre el derecho de acceso a la información sobre el ambiente: un repaso a la Directiva 90/313/CEE, Revista de Derecho Ambiental, núm. 13, 1994, pp. 119-164, entre otros.

${ }^{22}$ La Directiva 82/501/CEE del Consejo, de 24 de junio de 1982, relativa a los riesgos de accidentes graves en determinadas actividades industriales, conocida como Seveso I, ya establecía con anterioridad determinadas obligaciones de acceso a la información, si bien en casos puntuales.

23 Esta directiva supuso un cambio fundamental por cuanto por primera vez se impusieron a nivel comunitario obligaciones a las autoridades públicas de los Estados miembros en el campo del acceso del público a la información ambiental, hasta entonces sometido a la discrecionalidad interna de cada Estado. LOZANO CUTANDA, B., Administración y legislación ambiental, Dykinson, Madrid, 2005, p. 146.

${ }^{24}$ COM (2000) 400 final. El Informe consideró que la aplicación de la Directiva había tenido unos resultados positivos, pero también ciertas carencias que debían ser subsanadas. Por ejemplo, algunos Estados miembros habían interpretado la Directiva de forma muy restrictiva, lo que impedía el ejercicio efectivo del derecho de acceso a la información ambiental. Por eso, el Informe proponía clarificar las definiciones de información y de autoridades públicas, así como establecer medidas que favorecieran el ejercicio efectivo del derecho, entre otras.

${ }^{25}$ DOCE L 41/26 de 14/2/2003, con efectos desde el 14 de febrero de 2005. 
era mejorar el derecho de acceso a la información ambiental. Esta mejora se conseguiría, por una parte, teniendo en cuenta las observaciones hechas por la Comisión y, por otra, incorporando el contenido del Convenio de Aarhus en relación con el primer pilar, el derecho de acceso a la información ambiental. Por esta razón, una mera modificación de la Directiva anterior no era suficiente. Esta nueva directiva fijó como objetivo último hacer realmente efectivo el derecho de acceso a la información ambiental permitiendo un acceso real a esta información ${ }^{26}$. Actualmente también es exigible dicha transparencia a las instituciones de la Unión Europea ${ }^{27}$. Las instituciones comunitarias responden a la definición de autoridad pública del Convenio de Aarhus en igualdad de condiciones que las autoridades nacionales o locales.

\subsection{De la Ley 38/1995, de 12 de diciembre, sobre el derecho de acceso a la} información en materia de medio ambiente, a la Ley 27/2006, de 18 de julio, por la que se regulan los derechos de acceso a la información, de participación pública y de acceso a la justicia en materia de medio ambiente, y otras leyes sectoriales

En el Estado español, el artículo $45 \mathrm{CE}$ reconoce el derecho y el deber a un medio ambiente adecuado y hace un llamamiento a los poderes públicos para que velen por él. Pero no solo eso, sino que también reconoce a los ciudadanos una responsabilidad directa en la conservación de un medio ambiente adecuado ${ }^{28}$. Al ciudadano se le exigirá

\footnotetext{
${ }^{26}$ Tanto una directiva como la otra se aplicaban solo a la información ambiental de que disponían las autoridades competentes de los Estados miembros, pero no a la de las autoridades comunitarias; PLAZA MARTín, Derecho Ambiental..., cit., p. 331.

${ }^{27}$ Esto es así a partir de la Decisión 2005/370/CE del Consejo, de 17 de febrero, sobre la celebración, en nombre de la Comunidad Europea, del Convenio sobre el acceso a la información, la participación del público en la toma de decisiones y el acceso a la justicia en materia de medio ambiente. Cabe citar también aquí la Decisión de la Comisión, de 30 de abril de 2008, por la que modifica su Reglamento interno en lo que se refiere a las disposiciones de aplicación del Reglamento (CE) núm. 1367/2006 del Parlamento Europeo y del Consejo relativo a la aplicación, a las instituciones y a los organismos comunitarios, de las disposiciones del Convenio de Aarhus sobre el acceso a la información, la participación del público en la toma de decisiones y el acceso a la justicia en materia de medio ambiente, así como de la Directiva 2007/2/CE del Parlamento Europeo y del Consejo, de 14 de marzo de 2007, por la que se establece una infraestructura de información espacial en la Comunidad Europea (Inspire).

${ }^{28}$ LOZANO CUTANDA, B., Tratado de Derecho Ambiental, CEF, Madrid, 2014, p. 269. Como afirma la autora, "la Constitución ha reconocido este carácter del medio ambiente como un bien o interés colectivo, configurando el disfrute de un medio ambiente adecuado como un derecho de la comunidad en su conjunto, cuya realización se encomienda a los poderes públicos pero también a todos los integrantes de la comunidad, que tienen, como expresamente dice el art. $45 \mathrm{CE}$, no solo el derecho a disfrutar de un medio ambiente adecuado, sino también 'el deber' de conservarlo. [...] De esta responsabilidad se deriva no solo la obligación de una conducta cívica respetuosa con la conservación del entorno [...], sino que va más allá e implica a todos los ciudadanos en la tarea de la protección ambiental, para lo cual resulta necesario establecer herramientas legales que la hagan posible".
} 
actuar de forma correcta con el medio ambiente, pero también se le permitirá participar activamente en su protección. Por su parte, el artículo 9.2 CE prevé que los poderes públicos faciliten la participación de todos los ciudadanos en la vida política, económica, cultural y social.

El derecho al acceso a la información ambiental es uno de los medios fundamentales para facilitar esta participación. Este se desarrolló en nuestro ordenamiento jurídico, por primera vez, en el año 1995 a través de la Ley 38/1995, de 12 de diciembre, sobre el derecho de acceso a la información en materia de medio ambiente, en adelante, Ley 38/1995, que transpuso, tardíamente, la Directiva 90/313/CEE. Dicha transposición no estuvo exenta de debate.

En un primer momento, España entendió que la propia LRJ-PAC, en los artículos a los que nos hemos referido con anterioridad, en la redacción entonces vigente $^{29}$, comprendía el contenido de la Directiva y, por lo tanto, no debía promulgarse ninguna ley concreta que la transpusiera. Ni la doctrina española ni la Comunidad Europea lo entendieron así, ya que creyeron que esta era insuficiente por ser excesivamente restrictiva y, en consecuencia, no cubrir las exigencias europeas ${ }^{30}$. Finalmente ${ }^{31}$, se aprobó la Ley 38/1995, que se limitó a incorporar al derecho español las normas de la Directiva 90/313/CE que no comprendía la LRJ-PAC, de forma muy escueta ${ }^{32}$.

Esta ley permitía a todas las personas, físicas o jurídicas, nacionales o domiciliadas en uno de los Estados del Espacio Económico Europeo, el acceso a la información ambiental que estuviera en poder de las administraciones públicas competentes, sin la obligación de acreditar un interés determinado y con garantía, en todo caso, de confidencialidad sobre su identidad. También definía el concepto de derecho de acceso

\footnotetext{
${ }^{29}$ Artículos 3.5, 35 y 37 LRJ-PAC, entre otros.

${ }^{30}$ Entre otros autores, LOZANO CUTANDA cita como ejemplos de esta insuficiencia, primero, que la legitimación para acceder a la información se limita en la Ley 30/1992 a los "ciudadanos" y se requiere un "interés legítimo y directo" para acceder a documentos de carácter nominativo, y, segundo, que el plazo máximo de resolución de la solicitud de acceso a la información es de tres meses, más amplio que el que impone a los Estados la Directiva comunitaria; en Derecho Ambiental Administrativo, Dykinson, Madrid, 2007, p. 133.

${ }^{31}$ Cuando la Comisión ya había iniciado el procedimiento de infracción contra el Reino de España por incumplimiento de sus obligaciones comunitarias debido a la incorrecta transposición de la Directiva.

32 Como la transposición se produjo con retraso y de forma incorrecta, fue necesaria su posterior modificación por el artículo 81 de la Ley 55/1999, de 29 de diciembre, de medidas fiscales, administrativas y del orden social.
} 
a la información sobre el medio ambiente y el de Administración pública; los casos de denegación de la información; la difusión pasiva de la información mediante solicitud que debía ser resuelta en el plazo máximo de dos meses; el soporte en que debía suministrarse dicha información; la difusión activa de la información; la aplicación supletoria de la LRJ-PAC en todo lo no establecido por esta ley; y el desarrollo reglamentario de esta, el cual nunca tuvo lugar.

Posteriormente, y para introducir en el ordenamiento jurídico español la nueva Directiva sobre acceso a la información ambiental y el Convenio de Aarhus, a los que ya hemos hecho referencia, se promulgó la Ley 27/2006, objeto de nuestro estudio, mucho más amplia y completa.

La reciente promulgación de la Ley 19/2013 plantea a priori la cuestión de si afecta o modifica en algún término la aplicación de la normativa ambiental y, en consecuencia, la regulación ahí establecida. El artículo 5, dedicado a los principios, dispone en su apartado segundo lo siguiente: "[...] las obligaciones de transparencia contenidas en este capítulo se entienden sin perjuicio de la aplicación de la normativa autonómica correspondiente o de otras disposiciones específicas que prevean un régimen más amplio en materia de publicidad”. En consecuencia, será de aplicación toda aquella normativa que prevea un régimen más amplio en materia de publicidad. Podríamos analizar el alcance en este ámbito de la Ley 26/2007 para determinar cuál de las dos es aplicable, pero ello no será necesario puesto que los apartados 2 y 3 de la disposición adicional primera, con el título "Regulaciones especiales del derecho de acceso a la información pública", prevén lo siguiente: "Se regirán por su normativa específica, y por esta Ley con carácter supletorio, aquellas materias que tengan previsto un régimen jurídico específico de acceso a la información. [...] En este sentido, esta Ley será de aplicación, en lo no previsto en sus respectivas normas reguladoras, al acceso a la información ambiental y a la destinada a la reutilización". En definitiva, la aplicación de la Ley 19/2013 será supletoria en lo no previsto en la Ley 27/2006 en lo relativo al acceso a la información ambiental, tanto en el modo de difusión activa como previa solicitud $^{33}$. Este precepto abre la puerta a que se amplíen los deberes de transparencia en

\footnotetext{
33 Para mayor abundamiento del alcance de la aplicación de esta ley en términos generales, véase CASADO CASADO, L., "Estudio sobre el alcance de la supletoriedad de la Ley 19/2013, de 9 de diciembre, de transparencia, acceso a la información pública y buen gobierno sobre la Ley 27/2006, de 18 de julio, reguladora del derecho de acceso a la información ambiental", Revista Vasca de Administración Pública, núm. 99-100, 2014, pp. 819-946.
} 
aquello que no prevea la Ley específica ambiental, pero que sí prevea la Ley de Transparencia, como veremos posteriormente.

Por último, es imprescindible precisar que existe legislación ambiental sectorial que exige la difusión activa de determinada información ambiental y crea instrumentos a tal efecto. Sin ánimo de exhaustividad, cabe citar, en primer lugar, en el ámbito de las emisiones contaminantes, la creación de registros de emisiones y transferencia de contaminantes, que reciben el nombre de pollutant release and transfer registers (PRTR), creados tanto en el ámbito de la UE (EPER) como estatal E-PRTP), derivados del instrumento internacional Protocolo sobre Registros de Emisiones y Transferencias Contaminantes. En segundo lugar, la Ley del Ruido exige expresamente a las administraciones públicas competentes que informen sobre contaminación acústica, especialmente sobre los mapas de ruido y los planes de acción en materia de contaminación acústica ${ }^{34}$. Por último, en materia de planificación hidrológica, el Real Decreto 907/2007, de 6 de julio, por el que se aprueba el Reglamento de la Planificación Hidrológica, también hace previsiones al respecto.

\section{LA PUBLICIDAD ACTIVA O DIFUSIÓN ACTIVA Y EL ACCESO A LA INFORMACIÓN AMBIENTAL PREVIA SOLICITUD, DOS MODOS DE DIFUSIÓN DE LA INFORMACIÓN}

La Ley 27/2006 de acceso a la información prevé dos maneras de obtener la información que obre en poder de las autoridades públicas o en el de otros sujetos que la posean en su nombre dependiendo de quién impulse la difusión de esa información ambiental: la difusión activa de la información y la difusión pasiva de la información. La exposición de motivos se refiere a la difusión activa como el derecho a recibir información ambientalmente relevante por parte de las autoridades públicas, que deben recogerla y hacerla pública sin necesidad de que medie una petición previa. En este supuesto, la Ley impone unas obligaciones a las autoridades públicas para facilitar el acceso a la información. En el segundo caso, la difusión pasiva, el derecho consiste en buscar y obtener información que esté en poder de las autoridades públicas y no haya sido publicada. En este caso, se requiere una solicitud previa. Estas vías de difusión de

\footnotetext{
${ }^{34}$ Véanse, entre otros, LOZANO CUTANDA, B. (dir.), Comentario a la ley del ruido, ley 37/2003, de 17 de noviembre, Civitas, Madrid, 2004, y ALENZA GARCÍA, J.F. (dir.), El derecho contra el ruido, Aranzadi, Cizur Menor, 2013.
} 
la información se encuentran reguladas actualmente en el título II, "derecho de acceso a la información ambiental", de dicha Ley, que comprende los artículos 5 a $15^{35}$.

La Ley 27/2006 supone un cambio significativo en relación con la anterior Ley de Acceso a la Información Ambiental, ya que la Ley 38/1995 tan solo preveía, de forma muy genérica, la obligación de que las administraciones públicas publicaran información de carácter general sobre el estado del medio ambiente de forma periódica, que tendría carácter anual en el caso de la Administración general del Estado, sin más limitaciones que las previstas para el otorgamiento de información a solicitud de los interesados. Esto se traducía en la mera elaboración y publicación anual de una memoria sobre medio ambiente en España por parte del Ministerio del Medio Ambiente, donde se exponían los datos más relevantes sobre el estado de los recursos naturales del Estado español, las principales actuaciones llevadas a cabo por los poderes públicos y las directrices y prioridades futuras de la política ambiental. Las administraciones de las comunidades autónomas también elaboraban sus informes periódicos y otros documentos. Este cambio en la regulación de la difusión de la información se debió a la incorporación al ordenamiento jurídico español del Convenio de Aarhus y de la Directiva 2003/4/CE. El artículo 5 del Convenio de Aarhus propugna la recogida y difusión de las informaciones sobre medio ambiente con un redactado extenso y amplio, encomendando esta tarea a las autoridades públicas. Es en este artículo donde se instauran las bases en las que se inspirarán tanto la normativa europea como la legislación interna en relación con el derecho de acceso a la información ambiental. Entre estas obligaciones destacamos: aquellas dirigidas a las autoridades públicas para la recogida de información sobre el medio ambiente que sean útiles para el ejercicio de sus funciones; de las actividades propuestas y en curso con incidencia significativa del medio ambiente; y la difusión inmediata de informaciones en caso de amenaza

35 En relación con la difusión activa de la información ambiental, como manifiesta LOZANO CUTANDA, a diferencia de lo que ocurre en la difusión de la información ambiental previa solicitud, la Ley no reconoce un "derecho" a que se difunda información sobre el medio ambiente. No obstante, "tal derecho (y por consiguiente la legitimación para instar de los tribunales su protección) puede, sin embargo, entenderse incluido en una interpretación amplia del acceso a la información que obre en poder de las autoridades públicas en aquellos supuestos en los que, según lo expuesto, estas resultan obligadas a que se ponga a disposición de los ciudadanos, de oficio y periódicamente determinada información". LOZANO CUTANDA, Tratado de Derecho Ambiental..., cit., p. 286. Así también lo entendió la Sentencia del Tribunal Supremo de 4 de abril de 2006. La Sentencia se refiere a lo que denomina "difusión periódica de la información ambiental" y constata que, si bien el derecho a la información puede reconocerse de forma individual cuando se trata de solicitudes puntuales, tal derecho se transforma en un derecho a la difusión periódica medioambiental cuando el contenido de la información pretendida son datos de información periódica medioambiental de obligada medición por parte de las administraciones públicas. 
inminente para la salud o el medio ambiente. Por otro lado, también cabe destacar la referencia al modo de hacer accesible la información. En este sentido, las informaciones sobre el medio ambiente se deberán poner a disposición del público de forma accesible a través de redes públicas de telecomunicaciones; se publicarán regularmente un informe nacional e informes y propuestas; se difundirá la legislación ambiental; se informará a los consumidores sobre los productos; y se establecerán registros informatizados de contaminación.

En el ámbito de la Unión Europea y después de la aplicación de la Directiva 90/313/CE, un informe de la Comisión del año 2000, titulado "Informe sobre la experiencia adquirida en la aplicación de la Directiva 90/313", reveló, entre los aspectos problemáticos que obstaculizaban la realización plena del derecho de libre acceso a la información ambiental, el hecho de que las disparidades entre las disposiciones legales vigentes en los Estados miembros sobre el acceso a la información medioambiental que obre en poder de las autoridades públicas pudieran crear desigualdades dentro de la Comunidad por lo que se refiere al acceso a esta información o a las condiciones de la competencia, entre ellas, en el ámbito de la difusión activa de la información. Por esta razón, la Directiva 2003/4/CE amplió con la nueva regulación el nivel de acceso establecido en virtud de la Directiva 90/313/CE mediante mejoras propuestas por la Comisión. Estas eran el resultado, por una parte, del análisis de la experiencia adquirida en los años de implantación de esta directiva para intentar solventar los problemas que se detectaron en su aplicación y, por otra, de la necesidad de adecuar sus disposiciones a las exigencias del Convenio de Aarhus para proceder a su ratificación. Su objetivo principal es garantizar el derecho de acceso a la información medioambiental que obre en poder de las autoridades públicas y de otras entidades en su nombre, y establecer las normas y condiciones básicas, así como modalidades prácticas de su ejercicio, y garantizar que, de oficio, la información medioambiental se difunda y se ponga a disposición del público paulatinamente, con el objeto de lograr una difusión y puesta a disposición del público lo más amplia y sistemática posible (art. 1.a y b). Para ello deberá fomentarse, en particular, el uso de la tecnología de telecomunicación y/o electrónica, siempre que pueda disponerse de esta. Esto se traduce en sustituir la obligación genérica que hasta entonces regía por un listado de obligaciones concretas que incumben a los Estados miembros. La Directiva invita a los Estados miembros a adoptar las medidas necesarias para garantizar que las autoridades públicas organicen y 
actualicen la información sobre el medio ambiente perteneciente a sus funciones, que obre en su poder o en el de otra entidad en su nombre, con vistas a su difusión activa y sistemática al público, particularmente por medio de la tecnología de telecomunicación informática y/o electrónica, siempre que pueda disponerse de esta (art. 7.1) ${ }^{36}$, y además determina el contenido mínimo de la información que se debe difundir (art. 7.2). Asimismo, se prevé la publicación de informes nacionales y, según el caso, regionales y locales sobre el estado del medio ambiente, que deberán publicarse cada cuatro años o antes. Por otro lado, excluye la obligación de facilitar información mediante tecnologías de telecomunicación informática o electrónica de datos recogidos antes de la entrada en vigor de la Directiva, a menos que existan ya en forma electrónica. Cabe destacar, por último, el requerimiento a los Estados miembros de adoptar las medidas necesarias para que, en caso de amenaza inminente para la salud humana o el medio ambiente provocada por actividades humanas o por causas naturales, se difunda inmediatamente y sin demora toda la información que obre en poder de las autoridades públicas o de otras entidades en su nombre que permita, al público que pueda resultar afectado, la adopción de medidas para prevenir o limitar los daños provocados por la amenaza ${ }^{37}$. Por último, la Directiva permite que los Estados miembros mantengan o introduzcan medidas que prevean un acceso a la información más amplio que el exigido por esta.

Pasados once años de su promulgación, esta directiva continúa vigente. No obstante, se han aprobado otros instrumentos en el ámbito de la Unión Europea que permiten una mayor difusión de la información ambiental a manos de las instituciones de la Unión Europea y de los Estados miembros a través de la Directiva Inspire y del llamado SEIS.

En conclusión, la regulación establecida tanto en el Convenio de Aarhus como en la Directiva ha ido ampliando las exigencias en relación con los medios y el contenido de la información ambiental que se debe difundir, estableciendo una regulación muy

\footnotetext{
${ }^{36}$ La Directiva prevé, entre estos medios, las bases de datos electrónicas de fácil acceso al público a través de redes públicas de telecomunicaciones (art. 7.1 y 3), así como la creación de enlaces con direcciones de internet (art. 7.6).

37 Puede sorprender el detalle con que la Directiva regula esta obligación de difusión activa de la información ambiental, pero encuentra su explicación, en primer lugar, en la finalidad de evitar las desigualdades entre Estados miembros en relación con el acceso de la información, ya que para acabar con esta desigualdad se considera necesario establecer una regulación más específica de la difusión pasiva, y, en segundo lugar, como apuntan RAZQUIN y RUIZ DE APODACA, tiene su fundamento en adaptar la Directiva a los avances de las tecnologías de la información; en RAZQUIN LIZARRAGA y RUIZ DE APODACA ESPINOSA, Información..., cit., p. 63. Por esta razón se estableció como necesario elaborar "una directiva de segunda generación que refleje los cambios en la forma de crear, recoger, almacenar y transmitir información".
} 
detallada para la naturaleza de la norma, una directiva, aunque ello se fundamenta en que es el mejor modo para lograr la efectividad del derecho de acceso a la información ambiental en toda la Comunidad Europea por igual. Todo ello se ha visto reflejado en la transposición llevada a cabo a través de la Ley 27/2006.

\section{LAS OBLIGACIONES GENERALES DE DIFUSIÓN DE LA INFORMACIÓN AMBIENTAL}

Entre los objetos de la Ley 27/2006 se encuentra el de regular el derecho a acceder a la información ambiental que obre en poder de las autoridades públicas o en el de otros sujetos que la posean en su nombre (art. 1.a). Para hacer efectivo este derecho, se prevén, entre otras medidas, obligaciones dirigidas a las autoridades públicas en materia de información ambiental. Es concretamente el artículo 5 el que enumera las obligaciones generales en esta materia, que regirán tanto la difusión activa como la difusión pasiva de la información. Es necesario, en primer lugar, abordar el aspecto subjetivo de estas obligaciones, es decir, quién tendrá el deber de llevarlas a cabo. Asimismo, a raíz de la entrada en vigor de la Ley 19/2013 también deberemos analizar si ello comporta algún cambio en lo que a sujetos obligados se refiere.

\section{El ámbito subjetivo: los sujetos sobre los que recaen las obligaciones generales en materia de información ambiental}

De acuerdo con el capítulo I de la Ley 27/2006, "Obligaciones de las autoridades públicas en materia de información ambiental", serán las autoridades públicas las encargadas de dar cumplimiento a las obligaciones que se enumeran. La cuestión reside en saber qué se entiende por autoridad pública a estos efectos. La definición que establece el artículo 2.4 de la Ley responde a lo prescrito en el Convenio de Aarhus ${ }^{38}$ y en la Directiva europea ${ }^{39}$. Aunque la norma interna opta por hacer una clasificación

\footnotetext{
${ }^{38}$ El Convenio de Aarhus incluye cuatro categorías en la noción de autoridad pública: la Administración pública; las personas que ejercen, en virtud del derecho interno, funciones administrativas públicas; y cualquier persona que asuma responsabilidades o funciones públicas o preste servicios públicos relacionados con el medio ambiente bajo la autoridad de alguno de los anteriores; así como las instituciones de cualquier organización de integración económica regional. No quedan comprendidos los órganos e instituciones que actúan en ejercicio de poderes judiciales o legislativos (art. 2.2).

${ }^{39}$ La Directiva también contempla tres grupos diferenciados y concreta un poco más el concepto fijado en el Convenio: el primero, el Gobierno o cualquier otra Administración pública nacional, regional o local, incluidos los órganos consultivos; el segundo, las personas físicas o jurídicas que ejercen, en virtud del
} 
propia y distinta, en la práctica no supone ninguna diferencia real, sino más bien aparente $^{40}$.

La Ley 27/2006 acaba de concretar la definición adaptándola a la realidad de su territorio, aunque se trata de una definición muy abstracta y general. Divide las autoridades públicas en dos grandes grupos. En primer lugar, se refiere al Gobierno de la nación y a los órganos de gobierno de las comunidades autónomas ${ }^{41}$. En segundo lugar, a la Administración general del Estado, las administraciones de las comunidades autónomas, las entidades que integran la Administración local y las entidades de derecho público que sean dependientes o estén vinculadas al Estado ${ }^{42}$, a las comunidades autónomas o a las entidades locales. ${ }^{43}$ En tercer lugar, a los órganos públicos consultivos ${ }^{44}$, y, en cuarto y último lugar, a las corporaciones de derecho público y demás personas físicas o jurídicas cuando ejerzan, con arreglo a la legislación

derecho interno, funciones administrativas públicas, en particular tareas, actividades o servicios específicos relacionados con el medio ambiente; y el tercero, cualquier otra persona física o jurídica que asuma responsabilidades o funciones públicas o preste servicios públicos relacionados con el medio ambiente bajo la autoridad de una entidad o de una persona comprendida dentro de las categorías anteriores. Finalmente, establece la posibilidad de que los Estados miembros excluyan las entidades o instituciones en la medida en que actúen en calidad de órgano jurisdiccional o legislativo (art. 2.2).

${ }^{40}$ La Directiva 2003/4 que esta ley incorpora al derecho interno recoge las tres categorías del Convenio, si bien con distinta sistematización, ya que, además de comprender los poderes públicos, alcanza también a personas privadas que, bajo el control de los anteriores, desempeñan tareas de interés general relacionadas con el medio ambiente. Sobre este aspecto, véase RAZQUIN LIZARRAGA y RUIZ DE APODACA ESPINOSA, Información..., cit., p. 134 y ss.

${ }^{41}$ No se establece limitación alguna al respecto, con lo que incluye tanto los casos en que actúa con arreglo al derecho administrativo como cuando actúa conforme al derecho constitucional, los denominados "actos políticos". RAZQUIN LIZARRAGA y RUIZ DE APODACA ESPINOSA, Información..., cit., p. 138.

${ }^{42}$ Al referirse a entidades de derecho público como hace el artículo 2.2 LRJ-PAC, incluye no solo a los organismos públicos (organismos autónomos, entidades públicas empresariales y agencias estatales), sino también a las entidades gestoras de la Seguridad Social y a las fundaciones públicas sanitarias previstas en el artículo 11 de la Ley 50/1998, de 30 de diciembre. RAZQUIN LIZARRAGA y RUIZ DE APODACA ESPINOSA, Información..., cit., p. 138.

${ }^{43}$ En estos dos supuestos, el concepto no se limita aquí a las autoridades ambientales o relacionadas con el medio ambiente, sino a todas ellas. RAZQUIN LIZARRAGA y RUIZ DE APODACA ESPINOSA, Información..., cit., p. 138.

44 Por ejemplo, el Consejo de Estado, los consejos consultivos de las comunidades autónomas o el Consejo Asesor del Medio Ambiente. 
vigente, funciones públicas ${ }^{45}$, incluidos notarios y registradores de la propiedad mercantil y de bienes muebles ${ }^{46,47}$.

En un segundo apartado se entiende que tendrán la consideración de autoridad pública, a los solos efectos de lo previsto en los títulos I y II de la Ley, es decir, en lo que se refiere estrictamente al derecho de acceso a la información ambiental, las personas físicas o jurídicas cuando asuman responsabilidades públicas, ejerzan funciones públicas o presten servicios públicos relacionados con el medio ambiente bajo la autoridad de cualquiera de las entidades, órganos o instituciones previstos en el apartado anterior, es decir, los que hemos descrito en el párrafo precedente ${ }^{48}$. Cabe destacar la limitación al ámbito del derecho de acceso a la información ambiental, así como la referencia expresa a que estén relacionados con el medio ambiente y que desarrollen sus actividades bajo una de las actividades públicas comprendidas en el primer apartado ${ }^{49}$.

\footnotetext{
${ }^{45}$ Este grupo incluye la denominada Administración corporativa, por ejemplo, las cámaras de comercio y los colegios profesionales, y la Administración independiente, por ejemplo, el Consejo de Seguridad Nacional o la Comisión Nacional de la Energía. RAZQUIN LIZARRAGA y RUIZ DE APODACA ESPINOSA, Información..., cit., p. 141.

${ }^{46}$ De esta cuarta categoría cabe destacar que recoge las previstas en la segunda categoría de la normativa internacional y europea, pero con algunas variantes. Menciona expresamente las corporaciones de derecho público y los notarios y registradores y omite el adjetivo administrativa respecto de las funciones públicas y el inciso final "en particular tareas, actividades o servicios específicos relacionados con el medio ambiente", pero sin desvirtuar lo esencial, que es que estas personas ejerzan funciones públicas. En definitiva, se refiere a personas físicas y jurídicas que ejerzan, en virtud del derecho interno, funciones públicas.

${ }^{47}$ Las autoridades públicas incluidas en este primer bloque se entienden como tales a todos los efectos, sin exclusión alguna. Es decir, a efectos de los tres derechos que regula la Ley 27/2006: el de acceso a la información, el de participación pública y el de acceso a la justicia en materia de medio ambiente.

${ }^{48}$ Se trata de incluir aquellas personas que ostentan responsabilidades o funciones públicas o servicios públicos relacionados con el medio ambiente bajo el control de las autoridades de las categorías precedentes. RAZQUIN LIZARRAGA y RUIZ DE APODACA ESPINOSA, Información..., cit., p. 142. Aquí estarían englobados aquellos organismos del sector privado que desempeñan funciones públicas medioambientales relevantes como son los sectores del gas, la electricidad, los transportes y el agua, teniendo en cuenta la noción de "servicio público esencial". Por lo tanto, se pretende así dar cabida también a los sujetos privados en la definición de autoridades públicas, siguiendo el texto de los preceptos internacional y europeo, cumpliendo los dos requisitos que establece este artículo en relación con la atribución de responsabilidades públicas, el ejercicio de funciones públicas o la prestación de servicios públicos relacionados con el medio ambiente y el desarrollo de estas actividades bajo el control de una autoridad de las comprendidas en el apartado primero. RAZQUIN LIZARRAGA y RUIZ DE APODACA ESPINOSA, Información..., cit., p. 144.

${ }^{49}$ Para la doctrina es suficiente que las actividades desarrolladas guarden conexión, directa o indirecta, con el medio ambiente, sin necesidad de que se califiquen como estrictamente ambientales, tales como las actividades o servicios en los sectores de residuos, agua, energía y transporte. Se incluyen aquí las empresas o sociedades públicas y también las personas o empresas privadas no pertenecientes al sector público que gestionen servicios relacionados con el medio ambiente. RAZQUIN LIZARRAGA y RUIZ DE APODACA ESPINOSA, Información..., cit., p. 144.
} 
La Sentencia del Tribunal de Justicia de la Unión Europea (TJUE) conocida como caso Fish Legal Shirley resuelve la cuestión prejudicial planteada en torno a la inclusión en el concepto de "autoridad pública" de una sociedad mercantil que presta servicios públicos relacionados con el medio ambiente y que está bajo el control de una entidad o persona mencionada en el artículo 2.2 letras a) o b) de la Directiva. El Tribunal considera que dicha sociedad es autoridad pública si no determina con autonomía real la manera de prestar esos servicios, siempre que la información guarde relación con la prestación de esos servicios relacionados con el medio ambiente ${ }^{50}$.

A continuación, la Ley excluye del concepto de "autoridad pública" las entidades, órganos o instituciones cuando actúen en el ejercicio de funciones legislativas o judiciales, y cita expresamente las Cortes Generales, las asambleas legislativas de las comunidades autónomas, el Tribunal Constitucional, los juzgados y tribunales que integran el Poder Judicial, el Tribunal de Cuentas u órganos de fiscalización externa de las comunidades autónomas como órganos que, en todo caso, quedarán excluidos del ámbito de aplicación de esta ley cuando actúen en el ejercicio de funciones legislativas o judiciales ${ }^{51}$. Varias son las sentencias en las que el TJUE se ha pronunciado sobre esta cuestión. En el caso Deutsche Umwelthilfe, llega a la conclusión de que la facultad que otorga la Directiva a los Estados miembros de no considerar como autoridades públicas - es decir, obligadas a conceder el acceso a la información medioambiental que se encuentre en su poder - las "entidades o instituciones en la medida en que actúen en calidad de órgano [...] legislativo" no puede aplicarse a los ministerios cuando elaboran y adoptan disposiciones normativas de rango inferior a la ley ${ }^{52}$. Por su parte, la Sentencia conocida como caso Flachglas Torgau, en relación con el mismo precepto de la Directiva - artículo 2, punto 2, párrafo segundo, primera frase-, considera que dicha facultad otorgada a los Estados miembros puede aplicarse a los ministerios "en la medida en que participen en el procedimiento legislativo, en particular mediante la

\footnotetext{
${ }^{50}$ TJUE (Gran Sala), caso Fish legal y Emily Shirley contra Information Commissioner y otros. Sentencia de 19 de diciembre de 2013.

${ }^{51}$ En relación con este apartado, cabe decir que, a sensu contrario, estas exclusiones no regirán cuando tales órganos ejerzan otras funciones que no sean la legislativa o la judicial. En ese supuesto también estarán sometidas a las obligaciones que la Ley establece. Así se desprende de la STJUE de 9 de septiembre de 1999 C-217/97, Comisión/Alemania respecto de la Directiva 1990. Por otro lado, no quedan excluidos otros órganos constitucionales o de relevancia constitucional como son el Defensor del Pueblo y los comisionados autonómicos, que han de entenderse incluidos en el concepto de autoridad pública.

52 TJUE (Sala Segunda), caso Deutsche Umwelthilfe eV contra Bundesrepublik Deutschland. Sentencia de 18 de julio de 2013.
} 
presentación de proyectos de Ley o dictámenes”. Asimismo, considera que dicha facultad "no puede ejercitarse una vez que haya concluido el procedimiento legislativo de que se trate" ${ }^{, 53}$.

Tras esta exposición, cabe afirmar que la transposición de la definición de autoridad pública al derecho español es el desarrollo casi idéntico de la establecida en la Directiva 2003/4/CE. Cabe señalar que tanto la definición internacional como la europea y también la interna se asientan en un aspecto clave que no debemos perder de vista en ningún momento: el sintagma "funciones públicas". Toda autoridad pública, a efectos del derecho de acceso a la información ambiental, está sujeta, en todo caso, a que ejerza funciones públicas. Este será el aspecto más importante a tener en cuenta. Por lo tanto, se trata de un concepto funcional. Asimismo, cabe destacar que en las dos primeras categorías se ha suprimido la anterior referencia o limitación de que tengan funciones relacionadas con el medio ambiente, con lo que el abanico de autoridades públicas obligadas se amplía.

Debido a la amplitud, generalidad y complejidad de la definición de autoridad pública establecida en la norma, esta prevé también la obligación general de elaborar listas de autoridades públicas en atención a la información ambiental que obre en su poder, con la finalidad de detallar de forma exacta e inteligible qué autoridades públicas concretas comprende tal definición. Se prevé que estas listas se publiquen para conocer exactamente las autoridades públicas a las que la ciudadanía se podrá dirigir para obtener información, tanto de forma activa como pasiva. La norma exige al respecto que exista al menos una lista unificada de autoridades públicas por cada comunidad autónoma (art. 5.1.c), así como la posibilidad de designar unidades responsables de información ambiental (art. 5.3.a). En definitiva, con estas medidas se busca concretar y determinar la definición abstracta y genérica que la Ley establece y facilitar la tarea de saber a quién nos podemos dirigir para obtener información, así como aportar seguridad jurídica al respecto, ya que sabremos quién concretamente estará sometido a las obligaciones que se desprenden de esta ley, con el fin último de hacer efectivo el derecho de acceso a la información ambiental.

Es curioso que tanto la obligación de elaborar listas de las autoridades competentes como las otras obligaciones genéricas que apunta el artículo 5.1 de la Ley estatal se

\footnotetext{
${ }^{53}$ TJUE (Gran Sala), caso Flachglas Torgau GmbH contra Bundesrepublik Deutschland. Sentencia de 14 de febrero de 2012.
} 
dirijan, según la literalidad de la Ley, a las administraciones públicas, mientras que en los otros apartados del mismo artículo se habla de autoridades públicas. Esto nos puede llevar a pensar que las obligaciones establecidas en el primer apartado van dirigidas solo a las administraciones públicas, comprendidas en el artículo 2.4, apartado 1.b, de la Ley interna, pero tal interpretación parece errónea. Como hemos expuesto anteriormente, la voluntad del legislador europeo es englobar a todos los organismos que cumplan alguna función pública. Además, si tenemos en cuenta que una de las razones por las que la Directiva 2003/4/CE optó por adoptar la nueva definición de autoridad pública reside en la intención de evitar interpretaciones restrictivas, como había sucedido durante el período de aplicación de la Directiva anterior, esa interpretación no tendría sentido ${ }^{54}$. La doctrina española que se ha manifestado sobre este extremo entiende, por su parte, que no debe existir duda alguna de que en todo momento se está pensando en el término amplio de autoridades públicas, ya que la noción legal de autoridades públicas de la legislación interna ha de interpretarse desde el derecho de la Unión Europea ${ }^{55}$. La nueva definición de autoridad pública es mucho más amplia que la que establecían la Directiva 90/313 y la Ley 38/1995, que la transponía ${ }^{56}$.

\footnotetext{
${ }^{54}$ En algunos casos, los órganos de la Administración pública que no eran autoridades ambientales en sentido estricto del término aducían que sus responsabilidades no se relacionaban con el medio ambiente y se negaban por ello a dar información de carácter ambiental en su poder. Otro problema que se había planteado, concretamente en España, era que se excluía al Gobierno, al no aparecer mencionado en la Directiva, del deber de proporcionar información. LOZANO CUTANDA, Diccionario de Derecho ambiental..., cit., p. 726.

${ }^{55}$ Según RAZQUIN LIZARRAGA, esta redacción "no puede entenderse como una limitación respecto de la noción de 'autoridad pública', sino que tiende a garantizar el ejercicio del derecho de la información ante todas las autoridades públicas, bien en forma directa o bien en forma indirecta, cuando se trate de personas privadas", en Información..., cit., p. 175. Por lo tanto, las administraciones públicas actuarán, en ejecución de estas obligaciones, de intermediarias de las otras autoridades públicas para conseguir efectivamente el acceso a la información que obre en manos de todas las autoridades públicas.

${ }^{56}$ Esta directiva definía de forma muy sucinta qué entendía por autoridades públicas cuando preveía que era cualquier administración pública nacional, regional o local que tuviera responsabilidades y poseyera información relativa al medio ambiente, con excepción de los organismos que actuasen en ejercicio de poderes judiciales o legislativos (art. 2). El artículo 6 de la misma directiva extendía la obligación de divulgar la información a los organismos con responsabilidades públicas en materia de medio ambiente y bajo el control de las autoridades públicas. Esta definición tan genérica dio lugar a interpretaciones restrictivas por parte de los Estados miembros, lo que impedía un efectivo acceso a la información, ya que muchos organismos se negaban a dar la información por entender que estaban excluidos de tal definición. El Estado español fue uno de ellos, ya que la Ley 38/1995 se refería al derecho de acceso a la información disponible por las administraciones públicas competentes (arts. 1 y 2.1), entendiendo por tales las relacionadas en el artículo 2 de la LRJ-PAC. Por otro lado, obligaba a los empresarios, individuales o sociales, que gestionasen servicios públicos relacionados con el medio ambiente, bajo cualquiera de las modalidades establecidas en la legislación de contratos de las administraciones públicas, a facilitar la información relativa al medio ambiente que la Administración pública titular del servicio les solicitase, a los efectos de que esta pudiera cumplir con las obligaciones determinadas en esta ley (art. 2.2). Con esta redacción España interpretó, por ejemplo, que el Gobierno no estaba sometido a esta obligación. La Comisión entendió que con esta postura se estaba impidiendo el ejercicio efectivo del derecho de acceso a
} 
En definitiva, la interpretación del concepto de autoridad pública será siempre lo más amplia posible, adecuándose a los requisitos establecidos en la Ley, y a la luz de la Directiva de la UE, con el fin de hacer efectivo el derecho de acceso a la información ambiental.

La expresión autoridad pública no ha acabado de gustar al legislador español para designar al sujeto obligado a la difusión de la información pública $y$, en definitiva, a hacer efectivo el derecho de acceso a la información pública. La Ley 19/2013 opta por eliminar dicha terminología a la hora de determinar los sujetos obligados a la transparencia de la actividad pública. Tal expresión no aparece en la norma.

La Ley 19/2013 enumera de forma precisa los sujetos que de alguna manera u otra se verán obligados por la Ley y lo hace en varios artículos y apartados de acuerdo con las obligaciones que le serán impuestas a cada conjunto de sujetos según, principalmente, su naturaleza jurídica. Este modo de proceder, aunque parece un tanto confuso, no deja en principio duda alguna respecto a qué debe exigírsele a cada uno. Por eso, el artículo 2.1 trata de los obligados por el título I, "transparencia de la actividad pública", y el artículo 2.2 realiza una aclaración al respecto: “[...] a los efectos del título I se entienden por Administraciones públicas los organismos y entidades incluidas en las letras a) a d) del apartado primero" ${ }^{97}$. En diversos artículos posteriores, como el 6, el 7 y el 8, limita su aplicación a "los sujetos comprendidos en el ámbito de aplicación de este título", mientras que en otros apartados se refiere a las "Administraciones Públicas".

En aplicación de la Ley 19/2013 serán Administración pública en términos estrictos: a) la Administración general del Estado, las administraciones de las comunidades autónomas y de las ciudades de Ceuta y Melilla y las entidades que integran la Administración local; b) las entidades gestoras y los servicios comunes de la Seguridad Social, así como las mutuas de accidentes de trabajo y enfermedades profesionales

la información ambiental, por lo que decidió redefinir, en la nueva Directiva, el concepto de autoridad pública y hacerlo del modo más amplio posible para no dar opción a interpretaciones restrictivas por parte de los Estados miembros. Asimismo, recordemos que una de las funciones de esta directiva hoy vigente es incorporar el Convenio de Aarhus, que, como ya hemos visto, también establece una definición amplia de autoridad pública.

${ }^{57}$ Esta puntualización responde a la recomendación expuesta por el Consejo de Estado en el Dictamen 707/2012, de 19 de julio de 2012, del Anteproyecto de Ley de Transparencia, Acceso a la Información Pública y Buen Gobierno, según la cual resulta necesario precisar qué sujetos, a efectos de aplicación de la Ley, tienen la consideración de Administración pública, teniendo en cuenta que las obligaciones de publicidad activa del capítulo I, título I, no pueden imponerse con el mismo alcance a todos los entes, entidades y organismos incluidos en el artículo 2.1 y que existen distintos grados en la exigencia del cumplimiento de las obligaciones de publicidad activa previstas en la norma. 
colaboradoras de la Seguridad Social; c) los organismos autónomos, las agencias estatales, las entidades públicas empresariales y las entidades de derecho público que, con independencia funcional o con una especial autonomía reconocida por la Ley, tengan atribuidas funciones de regulación o supervisión de carácter externo sobre un determinado sector o actividad; y d) las entidades de derecho público con personalidad jurídica propia vinculadas a cualquiera de las administraciones públicas o dependientes de ellas, incluidas las universidades públicas. En cambio, los sujetos incluidos en las letras e) a h), a pesar de serles de aplicación también las disposiciones del mismo título I, "transparencia de la actividad pública", no son considerados Administración pública a los efectos de esta ley. Se trata de los siguientes sujetos: e) las corporaciones de derecho público, en lo relativo a sus actividades sujetas a derecho administrativo; f) la Casa de Su Majestad el Rey, el Congreso de los Diputados, el Senado, el Tribunal Constitucional y el Consejo General del Poder Judicial, así como el Banco de España, el Consejo de Estado, el Defensor del Pueblo, el Tribunal de Cuentas, el Consejo Económico y Social y las instituciones autonómicas análogas, en relación con sus actividades sujetas a derecho administrativo; g) las sociedades mercantiles en cuyo capital social la participación, directa o indirecta, de las entidades previstas en este artículo sea superior al $50 \%$; h) las fundaciones del sector público previstas en la legislación en materia de fundaciones; e i) las asociaciones constituidas por las administraciones, organismos y entidades previstos en este artículo. Se incluyen los órganos de cooperación previstos en el artículo 5 de la LRJ-PAC en la medida en que, por su peculiar naturaleza y por carecer de una estructura administrativa propia, les resulten aplicables las disposiciones de este título. En estos casos, el cumplimiento de las obligaciones derivadas de la presente Ley corresponderá a la Administración que ostente la secretaría del órgano de cooperación.

Por su parte, el artículo 3 de la Ley entiende por "otros sujetos obligados" aquellos a los que solo les serán de aplicación las obligaciones contenidas en el capítulo II del título I, "publicidad activa": a) los partidos políticos, organizaciones sindicales y organizaciones empresariales; y b) las entidades privadas que perciban durante el período de un año ayudas o subvenciones públicas de una cuantía superior a 100.000 euros o cuando al menos el $40 \%$ del total de sus ingresos anuales tengan carácter de ayuda o subvención pública, siempre que alcancen como mínimo la cantidad de 5.000 euros. 
Finalmente, el artículo 4, "Obligación de suministrar información", se refiere a las personas físicas y jurídicas distintas de las referidas en los artículos anteriores que presten servicios públicos o ejerzan potestades administrativas, las cuales estarán obligadas a suministrar a la Administración, organismo o entidad de las previstas en el artículo 2.1 a la que se encuentren vinculadas, previo requerimiento, toda la información necesaria para el cumplimiento por aquellos de las obligaciones previstas en el título I. Esta obligación se extenderá a los adjudicatarios de contratos del sector público en los términos previstos en el respectivo contrato.

Podemos afirmar que, como ya avanza el preámbulo de la misma Ley, nos encontramos ante un ámbito subjetivo muy amplio, mucho más amplio que en la Ley 27/2006. Sin embargo, también es cierto que no todos los sujetos están sometidos a las mismas obligaciones.

La duda que queda por resolver es en qué términos y hasta qué punto esta normativa es aplicable a la información ambiental, que tiene una normativa específica que la regula, la Ley 27/2006, que, como ya hemos estudiado, incluye las llamadas "autoridades públicas" como sujetos obligados. Como ya hemos avanzado, de la interpretación de la disposición adicional primera se desprende que prevalecerá la aplicación de la Ley 27/2006 por el hecho de establecer un régimen jurídico específico para el acceso a la información ambiental, si bien será de aplicación la Ley 19/2013 con carácter supletorio en lo no previsto en ella. La discusión reside en si el hecho de que la Ley 27/2006 regule los sujetos sobre los que recaen las obligaciones excluye directamente la aplicación de la Ley 19/2013 o, en cambio, a pesar de dicha regulación, también les sería aplicable la Ley 19/2013 en cuanto a las obligaciones que de ella se desprenden, ampliando así el abanico de sujetos obligados ${ }^{58}$. A nuestro entender, la regulación

\footnotetext{
${ }^{58}$ LOZANO CUTANDA considera que "hay que precisar, sin embargo, que este ámbito de aplicación de los deberes de transparencia no sustituye al previsto en la ley 27/2006, que sí regula este punto y no precisa, por tanto, de su aplicación supletoria. De esta forma, los sujetos mencionados por la ley 19/2013 (y no por la ley 27/2006) sí estarán sometidos a las obligaciones de difusión activa y previa solicitud de la información medioambiental, pero únicamente cuando se cumplan las condiciones contenidas en la ley de Transparencia, que son más restrictivas que las que rigen en materia medioambiental. Se requiere así, en especial que los contenidos o documentos que se soliciten hayan sido elaborados o adquiridos en el ejercicio de sus funciones (art.13), por lo que es preciso, a diferencia de lo que estipula la ley 27/2006, que tengan reconocidas competencias en materia de medio ambiente". LOZANO CUTANDA, Tratado de Derecho ambiental..., cit., p. 284. Para BLANES CLIMENT, "resulta contrario al principio de transparencia limitar las solicitudes de información ambiental únicamente a las reducidas autoridades públicas detalladas en la Ley 27/2006, cuando la ley 19/2013 ha incrementado el número de entidades públicas a la que se les puede solicitar información". BLANES CLIMENT, M.Á., "La incidencia de la nueva ley de transparencia en materia ambiental", Revista Aranzadi de Derecho Ambiental, núm. 28, mayo-agosto 2014, p. 146. En opinión de GUICHOT REINA, "ha de descartarse que la supletoriedad se
} 
establecida en la Ley 19/2013 no puede sustituir la prevista en la Ley 26/2007 en relación con los sujetos obligados a la difusión de la información en materia medioambiental, pero, sin embargo, sí que puede ampliar a otros sujetos, que no contempla la Ley 26/2007, obligaciones que, a pesar de ser generales de publicidad activa de información pública, puedan comprender aspectos medioambientales.

\section{El ámbito objetivo: las obligaciones generales en materia de información ambiental}

Las obligaciones generales, comprendidas en el artículo 5 de la Ley 27/2006 ${ }^{59}$, son actuaciones cuya finalidad es facilitar al público el acceso a la información ambiental. Según la literalidad del artículo, son las administraciones públicas las que tienen encomendadas estas tareas; sin embargo, cabe recordar que debemos interpretar este concepto de forma amplia.

En definitiva, este artículo fija las reglas generales de la actuación de las autoridades públicas en relación con la información ambiental, con la finalidad de garantizar la efectividad de los derechos y de la regulación de la norma ambiental. Para ello, exige que se informe al público de manera adecuada sobre los derechos que les otorga esta ley y sobre las vías para ejercer tales derechos (art. 5.1.a $)^{60}$.

Con esta obligación se pretende la difusión del contenido de la Ley 27/2006. Se deberán poner en conocimiento del público la posibilidad de ejercer el derecho de acceso a la información ambiental y el modo en que posteriormente podrá acceder a ella. De la lectura del artículo entendemos que esta obligación debe llevarse a cabo por los medios que se crean más oportunos, aunque posteriormente parece que se concretan en: distribución de libros informativos, información a través de las personas que atienden al

aplique al contenido sustantivo de estas normas, ampliándose el abanico de sujetos o límites; son aspectos regulados en cada caso del modo que se ha estimado conveniente para la materia en cuestión". GUICHOT REINA, Transparencia..., cit., p. 54.

${ }^{59}$ Este artículo no cuenta con otro similar en la Directiva, sino que guarda relación con las disposiciones generales establecidas en el artículo 3 del Convenio de Aarhus, aunque también advierte que no son obligaciones novedosas por cuanto agrupan en un solo precepto previsiones desgranadas a lo largo de la Directiva.

${ }^{60}$ Con ella se transpone la obligación impuesta a los Estados miembros de velar por que las autoridades públicas informen al público de manera adecuada sobre los derechos que les otorga la Directiva (art. 3.5 fin Directiva 2003/4/CE). 
público en las diferentes dependencias administrativas y difusión a través de las tecnologías de la información, en especial en las páginas web ${ }^{61}$.

Asimismo, se establece la obligación de que se facilite información para su correcto ejercicio, así como consejo y asesoramiento en la medida que resulte posible (art. 5.1.b). Esta obligación está inspirada en el mismo objetivo que la anterior, allanar el camino al acceso a la información ambiental. La primera de las actuaciones que se exige, facilitar la información para el adecuado ejercicio de los derechos, está relacionada con la obligación de informar sobre las vías para ejercer los derechos, ya que consistirá, como prevé el artículo 5.2.a del Convenio de Aarhus, en que las autoridades públicas pongan a disposición del público, de manera transparente, las informaciones sobre el medio ambiente y que esas informaciones sean efectivamente accesibles, en particular, proporcionando al público información suficiente sobre el tipo y el alcance de las informaciones sobre el medio ambiente que obren en poder de las autoridades públicas competentes, sobre las principales condiciones en que estén disponibles y sean accesibles esas informaciones y sobre el procedimiento que haya de seguirse para obtenerlas. En resumen, se explicará al público los medios que la Administración le ofrece para obtener la información ambiental. La segunda actuación se prevé para aquellos casos en que la persona no sepa cómo debe actuar y se dirija a la Administración a preguntarlo, la cual tendrá el deber de explicárselo y aconsejarle cómo debe actuar, dónde debe dirigirse, qué requiere, etc. Por lo tanto, tendrá la obligación de responder y resolver las dudas que el público plantee en relación con el acceso a la información. Sin embargo, este artículo acaba con la coletilla "siempre que sea posible", concepto jurídico indeterminado que permitirá no llevar a cabo esta obligación cuando no sea posible. Queda en el aire saber cuándo se estimará que no es posible asistir y dar consejo $^{62}$.

\footnotetext{
${ }^{61}$ Actualmente encontramos una amplia información acerca de las obligaciones de difusión de información ambiental de las administraciones públicas. En este sentido, destacan las memorias anuales, en las que se refleja cómo se da respuesta a estas obligaciones impuestas por la Ley. Por ejemplo, mediante este enlace accedemos a una memoria del 2012: $<$ http://www.magrama.gob.es/es/ministerio/servicios/informacion/Memoria datos 2012 tcm7319906.pdf >. Recuperado el 2 de febrero de 2015. En su página 2.002 y siguientes destacan las tareas realizadas al respecto.

${ }^{62}$ En la actualidad, en el portal web del Ministerio (MAGRAMA) encontramos el texto del Convenio de Aarhus y otra legislación y documentación relevante, informes nacionales de cumplimiento, informes estadísticos, iniciativas del Ministerio como actividades formativas, y enlaces de interés a las CC. AA. y otras instituciones. Asimismo, hoy en día existe la Oficina de Información Ambiental, que cumple dicha función de asesorar y dar consejo al público.
} 
También se obliga a elaborar listas de autoridades públicas en atención a la información ambiental que obre en su poder, las cuales se harán públicamente accesible, es decir, su acceso será público. A tal efecto, existirá al menos una lista unificada de autoridades públicas por cada comunidad autónoma (art. 5.1.c). Como ya hemos comentado con anterioridad cuando nos hemos referido al ámbito subjetivo, la Ley exige plasmar en una lista cuáles son concretamente las autoridades públicas a las que se refiere la definición reflejada en el artículo 2.4 de la Ley, con la finalidad de facilitar al público los nombres exactos de estas autoridades para que sepa concretamente a quién debe dirigirse. Se requiere una lista unificada por cada comunidad autónoma, por lo que en el Estado español habrá o debería haber diecisiete listas de las distintas autoridades públicas a las que podremos dirigirnos para acceder a información ambiental. Consideramos que estas listas tan solo tienen carácter enunciativo y en ningún caso son listas cerradas.

Asimismo, existe también la obligación de que las autoridades públicas garanticen que su personal asista al público cuando trate de acceder a la información ambiental (art. 5.1.d). Esta obligación vuelve a incidir en las obligaciones ya establecidas en primer y en segundo lugar, pero ahora focalizando y dirigiendo esta obligación a un sujeto concreto, el personal que asiste al público. Este inciso podría deducirse de las obligaciones anteriores, pero el legislador ha preferido plasmarlo expresamente para que no haya duda alguna. Con ello se complementa la responsabilidad directa, por parte de los titulares de unidades administrativas y personal encargados de la resolución o tramitación de los procedimientos, de adoptar las medidas oportunas para remover los obstáculos que impidan, dificulten o retrasen el ejercicio pleno de los interesados, disponiendo lo necesario para evitar y eliminar toda anormalidad en la tramitación de procedimientos (art. 41.1 LRJ-PAC). Así, se pretende añadir un plus a la responsabilidad ordinaria del personal encargado de los procedimientos, que, además de cumplir con las exigencias y los plazos, debe auxiliar a los solicitantes en el ejercicio de su derecho de acceso a la información ambiental mediante solicitud ${ }^{63}$.

También se habla de que se fomente el uso de tecnologías de la información y de las telecomunicaciones para facilitar el acceso a la información (art. 5.1.e). Esta obligación se ha traducido básicamente en dar acceso a la información ambiental a través de bases

\footnotetext{
${ }^{63}$ En este sentido, RAZQUIN LIZARRAGA y RUIZ DE APODACA ESPINOSA, Información..., cit., p. 177.
} 
de datos electrónicas que pueden ser consultadas desde internet y creando enlaces a direcciones electrónicas con contenido ambiental ${ }^{64}$. El uso del correo electrónico y las sedes electrónicas cada vez va más en aumento ${ }^{65}$. Por otro lado, cabe tener en cuenta la Ley 11/2007, de 22 de junio, de acceso electrónico de los ciudadanos a los Servicios Públicos ${ }^{66}$. Desde un ámbito general, supone un impulso para el fomento del uso de las tecnologías, también en el ámbito del acceso a la información en materia ambiental, ya que entre sus fines se contempla el de facilitar, por medios electrónicos, el acceso de los ciudadanos a la información y al procedimiento administrativo, con especial atención a la eliminación de las barreras que limiten dicho acceso (art. 3.2). El artículo 6.1 establece, por ejemplo, el derecho a relacionarse con las administraciones públicas utilizando medios electrónicos para el ejercicio de los derechos establecidos en el artículo 35 LRJ-PAC, así como para obtener información.

Por último, es necesario, en el marco de esta obligación, referirnos a la disposición adicional sexta, que prevé fórmulas de colaboración entre administraciones que faciliten la aplicación de la Ley 27/2006. Estas serán impulsadas por el Gobierno en el marco de los programas del Ministerio de Hacienda y Administraciones Públicas para el fomento de las tecnologías de información y comunicación. Asimismo, en el marco de este fomento, y concretamente en relación con la difusión pasiva de la información, se prevé la inclusión de procedimientos telemáticos relativos a la resolución de solicitudes de información ambiental en los registros telemáticos de la Administración general del Estado.

Además, existe la obligación de que se garantice el principio de agilidad en la tramitación y resolución de las solicitudes de información ambiental (art. 5.1.f). La Ley

\footnotetext{
${ }^{64}$ Actualmente, la mayoría de autoridades públicas y, sobre todo, las administraciones públicas cuentan con página web desde donde se puede acceder a una gran cantidad de información ambiental, bien sea directamente o a través de bases de datos o de enlaces electrónicos. Como ejemplo citamos la web del Ministerio de Agricultura, Alimentación y Medio Ambiente, www.magrama.gob.es, como ya hemos avanzado anteriormente.

${ }^{65}$ Así se desprende de los datos que contempla la Memoria de 2012 del Ministerio, a la que nos remitimos de nuevo.

${ }^{66}$ Reconoce el derecho de los ciudadanos a relacionarse con las administraciones públicas por medios electrónicos y regula los aspectos básicos de la utilización de las tecnologías de la información en la actividad administrativa, en las relaciones entre las administraciones públicas y en las relaciones de los ciudadanos con estas, con la finalidad de garantizar sus derechos, un tratamiento común ante ellas y la validez y eficacia de la actividad administrativa en condiciones de seguridad jurídica. Véase COTINO HUESO, L. y VALERO TORRIJOS, J. (coords.), Administración electrónica. La ley 11/2007, de 22 de junio, de acceso electrónico de los ciudadanos a los Servicios Públicos y los retos jurídicos del egobierno en España, Tirant lo Blanch, Valencia, 2010.
} 
establece un plazo máximo de resolución de las solicitudes de información ambiental de un mes desde la recepción de la solicitud en el registro de la autoridad pública competente, con carácter general, y de dos meses desde la recepción de la solicitud en el registro de la autoridad pública competente para resolverla si el volumen y la complejidad de la información son tales que resulta imposible cumplir el plazo de un mes. En este supuesto, deberá informarse al solicitante, en el plazo máximo de un mes, de toda ampliación de aquel, así como de las razones que lo justifican (art. 10.2 c).

Al incluir esta obligación en el marco general, es decir, la de garantizar el principio de agilidad tanto en la tramitación como en las solicitudes de información ambiental, el legislador ha querido reflejar la voluntad de satisfacer este derecho de acceso a la información ambiental con la mayor celeridad posible, por lo que no solo fija los plazos máximos en las obligaciones específicas, sino que insiste expresamente en la importancia de que las solicitudes se resuelvan rápidamente. La finalidad consiste en hacer efectivo el derecho de acceso a la información con la mayor brevedad posible, concretamente cuando la información sea suministrada de forma pasiva, fruto de una solicitud previa. El problema surgirá cuando no se dé cumplimiento a este mandato ${ }^{67}$.

Por otro lado, se afirma que las autoridades públicas velarán porque, en la medida de sus posibilidades, la información recogida por ellas o la recogida en su nombre esté actualizada y sea precisa y susceptible de comparación (art. 5.2).

Con estas palabras está exigiendo que la información sea de calidad. Para que sea de calidad, deberá cumplir estos tres requisitos que el propio artículo enumera: que la información esté actualizada, es decir, que no esté desfasada; que sea precisa y, por lo tanto, concreta, específica y detallada; y, por último, que sea comparable, esto es, que pueda ser objeto de comparación con otros datos o informaciones. En definitiva, una información objetiva, fiable y concreta ${ }^{68}$.

También se hace referencia a que las autoridades públicas adopten cuantas medidas sean necesarias para hacer efectivo el ejercicio del derecho de acceso a la información

\footnotetext{
${ }^{67}$ Sobre esta cuestión, véase BALLESTEROS MOFFA, L. Á., "La inactividad de la Administración frente al "derecho a saber" del ciudadano", Revista Jurídica de Castilla y León, núm. 33, mayo de 2014, en especial las pp. 16-21; "La ausencia de respuesta a las solicitudes y reclamaciones de acceso a la información pública: ¿el caballo de Troya de la transparencia?", Revista Española de Derecho Administrativo, núm. 161, 2014, pp. 75-100; y CASADO CASADO, L., "El derecho de acceso a la información ambiental a través de la jurisprudencia", Revista de Administración Pública, núm. 178, 2009, pp. 281-322.
}

${ }^{68}$ RAZQUIN LIZARRAGA y RUIZ DE APODACA ESPINOSA, Información..., cit., p. 179. 
ambiental, y señala algunas expresamente para que, como mínimo, se aplique una de ellas: designación de unidades responsables de información ambiental; creación y mantenimiento de medios de consulta de la información solicitada; y creación de registros o listas de la información ambiental que obre en poder de las autoridades públicas o puntos de información, con indicaciones claras sobre dónde puede encontrarse dicha información (art. 5.3).

La finalidad de este último mandato consiste en lograr la transparencia y la accesibilidad efectiva a la información ambiental. Se trata de establecer las modalidades prácticas necesarias para garantizar el ejercicio efectivo del derecho a la información ambiental, tal y como se plasma en el Convenio de Aarhus y en la Directiva 2003/4/CE ${ }^{69}$. Según el texto, las autoridades públicas podrán optar por tan solo una de las tres medidas que expresamente se nombran. Sin embargo, y en atención al mandato general de adoptar las medidas necesarias para garantizar el acceso efectivo a la información ambiental, debe considerarse que ello tiene carácter de mínimos y que se podrán adoptar hasta las tres medidas que se proponen, o incluso otras nuevas, con el fin de hacer efectivo el derecho.

Se incluye también la posibilidad de que la Administración general del Estado promueva la celebración de convenios de colaboración con el sector empresarial y con otras organizaciones para establecer puntos de información digitalizada a fin de cumplir las obligaciones en materia de información ambiental que la Ley prevé (disposición adicional séptima). La Ley nos proporciona otra medida que deberá ayudar a hacer efectivo el derecho de acceso a la información ambiental: la posibilidad de ampliar los puntos de información mediante otras vías de comunicación más allá de las autoridades públicas. A través de puntos de información digitalizada en empresas y organizaciones podremos acceder a la información ambiental.

En definitiva, todas las obligaciones generales que contempla la norma tienen una finalidad común, dar a conocer las posibilidades de acceder a la información ambiental que tienen en su poder las autoridades públicas y las vías para ejercer ese derecho. Hacer efectivo el derecho al acceso a la información ambiental estableciendo todos los

\footnotetext{
${ }^{69}$ Una vez más, se detallan medidas de cómo hacer efectivo el derecho de acceso a la información ambiental; como manifiesta LOZANO CUTANDA, aunque no es propio que una directiva descienda a fijar con detalle los procedimientos, se ha considerado necesario incluir algunos preceptos dirigidos a que los Estados introduzcan mejoras en las modalidades de puesta a disposición efectiva de la información sobre el medio ambiente teniendo en cuenta algunas técnicas que ya han sido experimentadas por diversos Estados; Diccionario de Derecho ambiental..., cit., p. 727.
} 
medios necesarios y adecuados para permitir el acceso de forma real a la información ambiental que obre en manos de las autoridades públicas. Todas estas obligaciones han supuesto cambios relevantes en el modelo clásico de actuación pública tanto a nivel organizativo como funcional desde 2006, año en que se promulgó esta normativa, hasta el día de hoy, con mayor o menor éxito. Además, ahora, con la entrada en vigor de la Ley 19/2013, ya no solo se pretende dicho cambio de mentalidad en materia ambiental y otros ámbitos sectoriales, sino de manera general ${ }^{70}$.

\section{LA DIFUSIÓN ACTIVA DE LA INFORMACIÓN AMBIENTAL}

\section{La difusión y puesta a disposición del público de la información ambiental: un elemento garantizado por la Ley 27/2006}

La difusión de la información ambiental es hoy en día fundamental. Vivimos en una sociedad donde la sensibilidad ${ }^{71}$ por estos aspectos cada día va a más y donde estamos sometidos a una infinidad de riesgos, la llamada sociedad del riesgo ${ }^{72}$, y, por lo tanto, el público quiere y necesita saber el estado de la cuestión de la legislación ambiental —en términos de conocer, por ejemplo, los límites permitidos de contaminación- y datos concretos como la cantidad de ozono que existe en el aire ${ }^{73}$ o los vertidos que se han

$70 \quad$ En

la web $<$ http://www.mma.es/secciones/info_estadistica_ambiental/estadisticas_info/memorias/2006/pdf/mem06 7_1_derechoaccesoinfamb.pdf $>$ podemos ver los distintos mecanismos que los ministerios, las direcciones generales, las comunidades autónomas y otros organismos han desarrollado para facilitar el acceso a la información ambiental en el ámbito de la difusión tanto activa como pasiva de la información ambiental. Como ejemplo, cabe destacar las oficinas o unidades de información y atención al ciudadano, que llevan a cabo una atención personalizada al público que comprende funciones de ayuda y orientación, como así se plasma en la Memoria a la que nos remitimos. Recuperado el 2 de febrero de 2015.

${ }^{71}$ Sobre la percepción social del medio ambiente, véase el documento recuperado el 26 de marzo de 2015 en

$<$ http://www.magrama.gob.es/ca/ministerio/servicios/informacion/Percepción_Social_del_Medio_Ambie nte_tcm8-189923.pdf>

${ }^{72}$ En relación con la sociedad del riesgo, véase BECK, U. y KROPP, C., "Environmental risk and public perceptions", Pretty, J. et ál., The SAGE handbook of environmenta and society, SAGE publications Ltd., 2008; y ESTEVE PARDO, José, "Derecho y medio ambiente: problemas generales; El Derecho del medio ambiente como Derecho de decisión y gestión de riesgos", Revista electrónica del Departamento de Derecho de la Universidad de La Rioja, REDUR, núm. 4, 2006, entre otros.

${ }^{73}$ En Cataluña, un estudio reciente elaborado por el Laboratorio del Centro de Medio Ambiente de la UPC ha puesto sobre la mesa la deficiencia en la transmisión de datos sobre determinadas partículas contaminantes en el ambiente a raíz de un estudio sobre la contaminación atmosférica en el Polígono Norte de Tarragona, entre otras cuestiones. 
realizado a las aguas ${ }^{74}$. Esta ley refleja esta necesidad y la importancia de que estemos informados sobre los aspectos medioambientales. En el marco del artículo 1 se establecen los derechos que tiene por objeto regular y se menciona expresamente como objeto de la Ley garantizar la difusión y puesta a disposición del público de la información ambiental, de manera paulatina y con el grado de amplitud, de sistemática y de tecnología lo más amplio posible. Cabe destacar dos aspectos: por una parte, la propia garantía de difundir la información y, por otra, cómo hacerlo. Esta difusión tiene que hacerse de manera paulatina y con el grado de amplitud, sistemática y de tecnología lo más amplio posible. Esta preocupación no solo existe en relación con los aspectos ambientales y de riesgo ambiental, sino que se extiende a todo aquello que sucede en lo público. Finalmente, el Estado español se ha decidido también a extender la transparencia a otros asuntos genéricos, sin limitarla solamente a lo sectorial. Dicha difusión activa está sometida a unos límites fijados legalmente que deben ser interpretados de forma restrictiva y que, en su caso y en la medida de lo posible, deben ser susceptibles de ser separados para dar estrictamente la información ambiental de interés, por ejemplo en casos de datos personales o de información confidencial.

\section{Los sujetos sobre los que recaen las obligaciones de difusión activa de la información ambiental y de la información pública}

Como vimos anteriormente, las obligaciones generales y también las de difusión activa de la información ambiental recaen sobre las llamadas "autoridades públicas", concepto que utiliza la Ley 27/2006 para describir los sujetos obligados por la ley y que ya hemos estudiado. Se trata de un concepto amplio y abstracto que, en definitiva, comprende a todo aquel que desarrolle funciones públicas, con los requisitos y las condiciones que la norma establece, según el caso. Cada comunidad autónoma concretó posteriormente este concepto a través de unos listados donde se recogen de forma nominativa dichos sujetos. Cabe recordar que de modo enunciativo, no conclusivo.

Para llevar a cabo estas obligaciones específicas de difusión de la información ambiental, la Ley llama a la actuación de las autoridades públicas. Pero, además, abre otra puerta a la participación de los operadores económicos en esta tarea de difundir la

\footnotetext{
${ }^{74}$ Como advierte RAZQUIN LIZARRAGA, dado que los datos que afectan al medio ambiente son de interés común y afectan a la colectividad, la difusión de los datos de actividades públicas o privadas que puedan tener incidencia sobre el medio ambiente es una exigencia; Información..., cit., p. 181.
} 
información ambiental. En este caso se prevé que de forma voluntaria los operadores económicos pongan a disposición del público de forma periódica una información concreta, la información sobre sus actividades o productos que tengan o puedan tener efectos significativos sobre el medio ambiente. Esta voluntariedad está vinculada al hecho de que las administraciones públicas promuevan esta tarea para los casos en que los operadores económicos no estén obligados legalmente a hacerlo ${ }^{75}$. Se trata de medidas de fomento para difundir la mayor información ambiental posible, no ya solo la que está en manos de las autoridades públicas, sino también aquella en manos de operadores económicos ${ }^{76}$.

En este caso se pretende que los operadores económicos informen a la sociedad sobre sus actividades o productos que tengan efectos significativos sobre el medio ambiente. La transparencia en la actividad de las empresas favorece a la sociedad en general, así como a la concienciación ambiental y a los procesos de participación. Esta invitación a las empresas de ser transparentes al dar información sobre sus productos y actividades aporta grandes beneficios. Por una parte, el operador económico pretenderá agradar al consumidor y ganarse su confianza, tanto la de él como la del público en general. Como estará “observado", queremos creer que adoptará todas las medidas a su alcance para actuar de la forma menos dañina posible, ya que, de lo contrario, la mala praxis podría acarrear efectos negativos en la propia empresa. Por otra, el hecho de que la difusión de la información sea voluntaria dará a entender que aquellos operadores económicos que no tengan nada que esconder por proceder correctamente en su actividad y productos tampoco tendrán ningún problema en poner a disposición del público información al

\footnotetext{
${ }^{75} \mathrm{La}$ disposición adicional duodécima prevé que las administraciones públicas promuevan que los operadores económicos, cuando no estén legalmente obligados a ello, informen periódicamente al público sobre aquellas de sus actividades o productos que tengan o puedan tener efectos significativos sobre el medio ambiente.

${ }^{76}$ Para un desarrollo sobre la difusión de información ambiental por parte de los operadores económicos, véase LOZANO CUTANDA, Derecho Ambiental..., cit., pp. 234 y ss.; Diccionario..., cit., p. 729 y ss.; y Tratado..., cit., pp. 298-303. La autora nos presenta los diferentes instrumentos internacionales y europeos a través de los cuales los operadores económicos son requeridos a presentar informes ambientales, bien de forma voluntaria, bien obligatoria. Por ejemplo, el conocido como Convenio de Lugano, Convenio del Consejo de Europa sobre responsabilidad civil por los daños ocasionados al medio ambiente por actividades peligrosas, firmado el 21 de junio de 1993, del que no forma parte ni la Unión Europea ni España, establece la obligación de que los operadores de actividades peligrosas para el medio ambiente faciliten dicha información a las posibles víctimas de dicha actividad. Otro ejemplo son las auditorías ambientales, bien a través del sistema europeo de ecogestión y ecoauditoría, sistema EMAS III, o a través de sistemas privados de normalización como la ISO 14.000. También destaca la Resolución de 25 de marzo de 2002 (BOE de 4 de abril) "para el reconocimiento, valoración e información de los aspectos medioambientales de las cuentas", por la que se obliga a las entidades que han de presentar cuentas anuales individuales y consolidadas (tanto si se trata de empresas como de entidades sin ánimo de lucro) a incluir en su contabilidad determinados datos relativos a su actividad medioambiental.
} 
respecto. En cambio, aquel que opte por el secretismo puede dar a entender que no le interesa que se sepan los efectos significativos sobre el medio ambiente de sus actividades o de sus productos, probablemente porque los procesos que sigue son mejorables medioambientalmente hablando.

Parece constatarse en la sociedad que, por ejemplo, la incorporación de determinados datos relativos al comportamiento ambiental de las empresas en sus cuentas anuales se convierte cada vez más en una necesidad no solo relevante para el público en general, sino también de sumo interés para entidades de seguro y crediticias, posibles inversores, accionistas y clientes en general de la empresa, dada la cada vez mayor trascendencia jurídica y económica que para los beneficios y costes de una empresa tiene su situación ambiental $^{77}$. Asimismo, existen ámbitos en los que sí que se les exige una cierta transparencia, como en el caso del etiquetado de los productos y la información que debe constar, entre otros.

En conclusión, la sociedad en general también demanda información sobre las empresas y los operadores económicos en la medida en que su actividad afecta tanto a la salud de las personas como al medio ambiente. La transparencia de las empresas en este aspecto y el buen actuar en su cadena de producción, además, benefician a la propia empresa, ya que, cuanto más cuidadosa con el medio ambiente sea, mejor la va a valorar la sociedad.

La Ley 19/2013, por su parte, impone distintas obligaciones según el sujeto de que se trate. Recordemos que no se habla de autoridad pública, sino de Administración pública y de otros sujetos sometidos al título I de la Ley. Este título I, llamado "Transparencia de la actividad pública", a su vez está dividido en capítulos: el I está dedicado al ámbito subjetivo de aplicación; el II, a la publicidad activa; y el III, al derecho de acceso a la información pública. El capítulo I realiza una enumeración de los sujetos obligados por esta ley, estableciendo una previa distinción conceptual que afectará a las obligaciones a las que estén sometidos los distintos "grupos" de sujetos. Por ejemplo, los partidos políticos y los sindicatos estarán sometidos a las obligaciones del capítulo II, es decir, de publicidad activa, pero no así a las del capítulo III, sobre acceso a la información pública. Son, sin embargo, los artículos del capítulo II los que detallan a qué está obligado cada sujeto. El artículo 5, "principios generales", se refiere de forma muy genérica a las obligaciones, la normativa específica aplicable, en su caso, los límites y

${ }^{77}$ LOZANO CUTANDA, Tratado..., cit., p. 300. 
los medios de difusión; el artículo 6, "información institucional, organizativa y de planificación", distingue las obligaciones entre "los sujetos comprendidos en el ámbito de aplicación de este título" y "las Administraciones públicas”. El artículo 7, "información de relevancia jurídica", afecta solamente a "las Administraciones públicas", mientras que el artículo 8, “información económica, presupuestaria y estadística", se dirige a "los sujetos incluidos en el ámbito de aplicación de este título".

Finalmente, cabe mencionar que el artículo 10 prevé que "la Administración General del Estado desarrolle un Portal de la Transparencia, dependiente del Ministerio de la Presidencia, que facilite el acceso de los ciudadanos a toda la información a la que se refieren los artículos anteriores relativa a su ámbito de actuación”. Es decir, que la Ley prevé este medio para facilitar la publicidad activa prevista en el título I. Este portal se puso en funcionamiento el mismo día en el que la entrada en vigor de la Ley lo hacía exigible $^{78}$. Asimismo, también se ha promulgado el Real Decreto 919/2014, de 31 de octubre, por el que se aprueba el Estatuto del Consejo de Transparencia y Buen Gobierno.

\section{Las obligaciones específicas en materia de difusión activa de información ambiental}

El objeto de la Ley de garantizar la difusión de la información ambiental viene desarrollado por el artículo 6 de la propia ley, donde se hace hincapié en cómo deberá llevarse a cabo esta difusión de la información y a través de qué medios.

El primer mandato consiste en que las autoridades públicas adopten las medidas necesarias para conseguir tres objetivos en relación con la difusión de la información. El primero, que la difusión se realice de forma paulatina. La información deberá ser actual y, por lo tanto, deberá actualizarse continuamente y día tras día o, por lo menos, cuando existan cambios y la información difundida ya no se corresponda con la realidad. La periodicidad con la que se actualice dependerá de la información ambiental de que se trate: informes anuales, datos sobre contaminación (diarios), etc. Por esta razón, la información se difunde poco a poco, paulatinamente. El segundo, que se haga de la manera más amplia posible, siempre teniendo en cuenta la relevancia de la información. Del artículo se desprende que, cuando se refiere a que dicha información debe ser

\footnotetext{
${ }^{78}<$ http://transparencia.gob.es/es_ES/>
} 
amplia, dicha amplitud estará limitada por la relevancia de la información. Y el tercero, que la puesta a disposición del público de esta información se lleve a cabo de la forma más sistemática posible. Con este fin se pretende difundir la información de la manera más fácil, entendible y organizada posible para el público. Se trata de requisitos formales exigidos a la difusión de la información ambiental. Para conseguir tales fines, la Ley dispone que las autoridades públicas deben, en primer lugar, organizar y actualizar la información relevante para sus funciones que obre en su poder o en la de otra entidad en su nombre, todo ello con vistas a su difusión activa y sistemática entre el público. De este modo, para ofrecer una información paulatina, amplia y sistemática, primero deberá organizarse y actualizarse la información que sea relevante.

En segundo lugar, se exige el uso de las tecnologías de la información y de las telecomunicaciones, siempre que pueda disponerse de estas, para proceder a la difusión de la información. En relación con los medios a través de los cuales se difundirá la información ambiental, la Ley no solo hace una referencia general a las tecnologías de la información y las telecomunicaciones, sino que también concreta dos formas a través de las cuales se verá cumplida esta obligación: mediante la utilización de bases de datos electrónicas de fácil acceso al público a través de redes públicas de telecomunicaciones y con la creación de enlaces con direcciones electrónicas a través de las cuales se pueda acceder a la información. Finalmente, se dispone que la Administración general del Estado deberá mantener actualizado un catálogo de normas y de resoluciones judiciales sobre aspectos claves de la Ley, que hará públicamente accesible de la manera más amplia y sistemática posible ${ }^{79}$.

Todos los sujetos enumerados en el artículo 2.1 de la Ley 19/2013 están obligados a "publicar de forma periódica y actualizada la información cuyo conocimiento sea relevante para garantizar la transparencia de su actividad relacionada con el funcionamiento y control de la actuación pública" (art. 5.1). Se trata de una definición muy genérica, muy amplia y muy indeterminada, ya que desconocemos a priori cuál debe ser concretamente dicha información cuyo conocimiento será relevante para

\footnotetext{
${ }^{79}$ Hoy en día disponemos de esta información sobre todo en formato electrónico a través de las páginas web de las instituciones. Por ejemplo, el Ministerio de Agricultura, Alimentación y Medio Ambiente pone a disposición del público su página web y el espacio dedicado a la información ambiental: www.magrama.gob.es/es/ministerio/servicios/informacion/informacion-ambiental. Por ejemplo, encontramos los informes nacionales de cumplimiento e informes estadísticos, entre otros.
} 
"garantizar la transparencia de su actividad relacionada con el funcionamiento y control de la actuación pública" ${ }^{\prime 0}$.

Además de hacer prevalecer la normativa específica y más concreta sobre la materia, el artículo 5.3 de la Ley 19/2013 nos remite a los límites a dicha publicidad de la información establecidos en los artículos 14 y 15 de la misma ley, haciendo especial hincapié en la protección de datos de carácter personal ${ }^{81}$, en relación con la cual añade que "a este respecto, cuando la información contuviera datos especialmente protegidos, la publicidad sólo se llevará a cabo previa disociación de los mismos” ${ }^{\text {" }}$. Es importante detenernos aquí, ya que esto plasma expresamente la necesidad de disociar aquellos datos que no se pueden publicar de los que sí. En materia medioambiental se ha venido dando una práctica poco deseada de denegar datos ambientales sobre la base del principio de confidencialidad, de protección de datos, etc. Sin embargo, tanto la doctrina como la jurisprudencia han abogado por la necesidad de disociar los datos que están sometidos a dicho principio y a dicha protección de los datos que se piden en este caso con relevancia ambiental, reclamando así que se dé publicidad y acceso a estos últimos disociándolos de los protegidos ${ }^{83}$. A nuestro entender, es un gran avance y un logro que esta ley disponga expresamente que "cuando la información contuviera datos especialmente protegidos, la publicidad sólo se llevará a cabo previa disociación de los mismos", ya que ello comporta que la información se tenga que dar, aunque previa disociación de estos datos, no que se deniegue como en muchos casos ha sucedido.

En lo que al medio de publicación se refiere, también apuesta por la difusión vía electrónica cuando obliga a publicar la información sujeta a las obligaciones de

\footnotetext{
${ }^{80}$ Como apunta LOZANO CUTANDA, “estamos aquí, por tanto, ante una información distinta a la medioambiental a la que se refiere la Ley 27/2006 (aunque pueda coincidir en algún punto), pues se trata de informar sobre el funcionamiento del servicio y mecanismos de control. Por consiguiente, este deber de difusión se añade al contemplado en la Ley 27/2006”. LOZANO CUTANDA, Tratado..., cit. p. 287.

${ }^{81}$ Sobre la protección de datos, véanse PIÑAR MAÑAS, J. L., "Transparencia y protección de datos: Las claves de un equilibrio necesario", García Macho, R. (ed.), Derecho administrativo de la información y Administración transparente, Marcial Pons, Madrid, 2010; GUICHOT, E., "Transparencia versus protección de datos", Blanes Climent, M. A., La transparencia informativa de las Administraciones públicas, Aranzadi, Cizur Menor, 2014, pp. 315-326.

${ }^{82}$ El informe de la Asociación Española de Protección de Datos (AEPD) recomendó añadir esta frase, tal como se hizo en la versión final, a la referencia expresa a la protección de datos como límite aplicable también a la publicidad activa. Véase GUICHOT REINA, Transparencia ..., cit., p. 151.

${ }^{83}$ OLLE RUBERT, M., "Comentario a la sentencia del tribunal de justicia de la Unión Europea de 14 de febrero de 2012: el derecho de acceso a la información en materia de medio ambiente y sus restricciones", Revista Aranzadi de Derecho Ambiental, núm. 24, 2013, pp. 171-180.
} 
transparencia en las correspondientes sedes electrónicas o páginas $\mathrm{web}^{84}, \mathrm{y}$, preferiblemente, en formatos reutilizables, y de una manera clara, estructurada $y$ entendible para los interesados (art. 5.4). Asimismo, prevé lo siguiente: "Se establecerán los mecanismos adecuados para facilitar la accesibilidad, la interoperabilidad, la calidad y la reutilización de la información publicada así como su identificación y localización”.

Cabe resaltar no solo el medio, sino también el cómo deberá ser dicha información: clara, estructurada y entendible ${ }^{85}$ para los interesados (y preferiblemente en formatos reutilizables). Dado que la Ley ambiental prevé que la información se difunda de forma amplia y sistemática, entendemos que el último adjetivo es sinónimo de estructurada. Asimismo la referencia a que la información sea reutilizable es la nomenclatura hoy en día adoptada, desde la promulgación de la ley 37/2007, a la descripción que hace la ley 27/2006 de cómo debe ser la información, en relación con los enlaces Web, listados, etc. Las memorias elaboradas por el MAGRAMA son un ejemplo de ello.

Por otro lado, es importante destacar que se exige que la información sea entendible para los interesados. La Ley 27/2006 lo exige expresamente para los informes sobre el estado del medio ambiente, pero entendemos que debería ser siempre así.

\section{El contenido mínimo de la información ambiental objeto de difusión activa}

En el ámbito de la difusión activa de la información ambiental, la Ley 27/2006 no solo establece de qué modo y a través de qué medios debe difundirse esta información, sino que también hace referencia a la información que debe difundirse. La propia Ley, reproduciendo la Directiva 2003/4/CE, establece un listado de información a difundir que supondrá el contenido mínimo de la información ambiental que las autoridades públicas deberán difundir activamente. Bajo la condición de que la información esté actualizada, exige que esta se refiera, como mínimo, a los siguientes extremos:

- Los textos de tratados, convenios y acuerdos internacionales y los textos legislativos comunitarios, estatales, autonómicos o locales sobre el medio ambiente o relacionados con la materia. Es absolutamente básico y necesario que esta información

\footnotetext{
${ }^{84}$ Durante la tramitación del texto legal se debatió si había que poner la disyuntiva $o$, o, en cambio, poner la conjunción $y$. Al final se dejó la propuesta inicial, lo que limita la publicidad por cuanto no todo el mundo tiene acceso a las sedes electrónicas. Véase GUICHOT REINA, Transparencia..., cit., p. 156.

${ }^{85}$ Es de notar que las exigencias del apartado 4 fueron sugeridas en la consulta pública, ya que el anteproyecto no las contemplaba. Véase GUICHOT REINA, Transparencia ..., cit., p. 151.
} 
se ponga en conocimiento del público, y que ello se haga siguiendo las pautas a las que nos hemos referido anteriormente, es decir, de forma sistemática, organizada, actualizada y amplia. El público debe conocer la normativa vigente en materia ambiental, sobre todo para poder posteriormente ejercer otros derechos como el de participación y el de acceso a la justicia. Dada la gran cantidad de normativa ambiental o relacionada con temas ambientales y su complejidad, será necesario que su difusión se realice del modo más accesible y comprensible posible para todo el público.

- Las políticas, los programas y los planes relativos al medio ambiente, así como sus evaluaciones ambientales, en su caso. A través de esta publicidad el público puede conocer concretamente las actuaciones que van a llevarse a cabo en un futuro en el área ambiental en un ámbito determinado, lo que le dará también la posibilidad de participar o actuar al respecto. Cabe señalar que durante la tramitación de dichas políticas, planes y programas ambientales también se abre un período de participación, así que actualmente ya se da publicidad a estos planes, una vez aprobados, en los boletines oficiales. La Ley estatal ha optado por añadir la obligación de informar sobre "sus evaluaciones ambientales cuando proceda". La Directiva se refiere tan solo a las políticas, los programas y los planes relacionados con el medio ambiente.

- Los informes sobre los avances registrados en materia de aplicación de la normativa ambiental y relacionada con el medio ambiente y de aplicación de las políticas, los planes y los programas ambientales, así como sobre las evaluaciones ambientales cuando estas hayan sido elaboradas en formato electrónico o mantenidas en dicho formato por las autoridades públicas. La evaluación de la aplicación de la legislación, las políticas, los planes y los programas ambientales también debe estar a disposición del público, aunque parece que se limite tan solo a los informes que hayan sido elaborados en formato electrónico o mantenidos en ese formato por las autoridades públicas, lo que da lugar a que, cuando esto no suceda, no se le dé la publicidad requerida, aspecto que consideramos poco justificado y puede llevar a las autoridades públicas que no estén interesadas en difundir tal información a no editarla en formato electrónico, con lo que el público tan solo tendrá acceso a esa información mediante solicitud $^{86}$.

\footnotetext{
${ }^{86}$ Cada administración debe realizar un análisis sobre el grado de cumplimiento de la legislación ambiental que en el ejercicio de sus competencias le corresponde aplicar, inspeccionar y sancionar. Con estos datos elaborará un informe que debe ser público, según RAZQUIN LIZARRAGA y RUIZ DE APODACA ESPINOSA, Información ..., cit., p. 188. A día de hoy vemos que sí que se está haciendo.
} 
- Los informes sobre el estado del medio ambiente que elaborarán y publicarán las administraciones públicas. Por una parte, un informe de coyuntura sobre el estado del medio ambiente que elaborarán, como mínimo, cada año y, por otra, un informe completo que se realizará cada cuatro años. Estos informes serán de ámbito nacional y autonómico, y, en su caso, local, e incluirán datos sobre la calidad del medio ambiente y las presiones que este sufra, así como un sumario no técnico que sea comprensible para el público. La Ley exige expresamente a las administraciones públicas, la Administración general del Estado, las administraciones autonómicas y las administraciones locales ${ }^{87}$ la elaboración y publicación de dos tipos de informes, uno anual o incluso más frecuente, llamado informe de coyuntura, y un segundo informe, este de carácter cuatrienal, denominado informe completo ${ }^{88}$. Tanto el uno como el otro deberán incluir datos sobre dos aspectos: la calidad del medio ambiente y las presiones que sufra. Por otra, se deberá añadir un resumen en un lenguaje no técnico ni científico para que el público pueda entenderlo fácilmente ${ }^{89}$. El informe de coyuntura deberá analizar el estado del medio ambiente. El informe completo también, pero, como el propio nombre indica, deberá ser más detallado.

- Los datos o resúmenes de los datos derivados del seguimiento de las actividades que afecten o puedan afectar al medio ambiente. En algunos ámbitos sectoriales ya disponemos desde hace unos años de datos sobre el seguimiento de actividades que afectan o puedan afectar al medio ambiente. En ocasiones la actualización es inmediata y directa, como en el caso de la cantidad de ozono o azufre en el aire. No obstante, nos

\footnotetext{
${ }^{87}$ En este último caso la Ley solo lo exige, "en su caso". Deberá verse cuándo se entiende que se da tal caso.

${ }^{88}$ La Directiva tan solo hace referencia al segundo informe cuatrienal, ya que prevé que los Estados miembros adopten las medidas necesarias para asegurar la publicación, a intervalos regulares que no superen los cuatro años, de informes nacionales y, según el caso, regionales o locales sobre el estado del medio ambiente. Vemos también que la Ley estatal ha optado por la obligatoriedad de los informes autonómicos. El Ministerio de Medio Ambiente (hoy MAGRAMA) y las administraciones autonómicas ya venían elaborando con la ley anterior informes anuales donde se exponían los datos más relevantes sobre el estado de los recursos naturales del Estado español, las principales actuaciones llevadas a cabo por los poderes públicos y las directrices y prioridades futuras de la política ambiental. Las administraciones de las comunidades autónomas también elaboraban sus informes periódicos y otros documentos. Esto justifica que se haya querido seguir con esta práctica para así disponer de más información o, como mínimo, con más frecuencia y, como exige la norma, paulatinamente. Esto también puede justificar que se haya optado por obligar también a las administraciones autonómicas a hacerlo, ya que ya venían haciéndolo anteriormente. A día de hoy, en la página web del MAGRAMA encontramos "informes nacionales de cumplimiento" de los años 2008, 2010 y 2013 para cumplir las exigencias del Convenio de Aarhus, así como "informes estadísticos" de los años 2008, 2009, 2010, 2011, 2012 y 2013.

${ }^{89}$ Este último requisito no lo preveía la Directiva, pero resulta evidente su necesidad para hacer plenamente efectivo el derecho; una muestra de su importancia es que la Ley 19/2013 lo ha incorporado como requisito en términos generales.
} 
debemos preguntar qué actividades serán objeto de seguimiento y qué datos se pondrán a disposición del público a través de la red y también quién se encargará de publicar esos datos y con qué periodicidad. En este punto parece que la discrecionalidad es bastante amplia, excepto cuando una norma sectorial concreta tales extremos y obliga a tal publicidad.

Las autorizaciones con un efecto significativo sobre el medio ambiente y los acuerdos en materia de medio ambiente. En su defecto, la referencia al lugar donde se puede solicitar o encontrar la información de conformidad con lo dispuesto en el artículo $5^{90}$. También se exige esta publicidad a través de internet u otros medios de los acuerdos en materia de medio ambiente. No obstante, la Ley permite no hacerlo, aunque en ese caso se nos debe informar de cómo podemos llegar a esa información. Este segundo camino es más dificultoso, con lo que se pierde efectividad en el derecho de acceso a esa información, aunque sigue existiendo tal derecho ${ }^{91}$.

- Los estudios sobre el impacto ambiental y evaluaciones del riesgo relativos a los elementos del medio ambiente mencionados en el artículo 2.3.a. En su defecto, una referencia al lugar donde se puede solicitar o encontrar la información de conformidad con lo dispuesto en el artículo 5.

Cabrá tener en cuenta, respecto a esta exigencia, las disposiciones de la Ley 21/2013, de 9 de diciembre, de Evaluación Ambiental, en relación con los planes y programas con incidencia ambiental sometidos a evaluación ambiental. Además, esta nueva ley adelanta los deberes de publicidad por cuanto exige que se consulte con las personas afectadas el primer borrador del plan y, luego, una vez elaborada su versión inicial, se someta a información pública junto con el estudio ambiental estratégico. También cabe destacar la disposición adicional decimocuarta de esta misma ley, que encomienda a las

\footnotetext{
90 Como manifiesta BLANES CLIMENT, "respecto las autorizaciones ambientales integradas, las Comunidades autónomas tienen la obligación de publicar las resoluciones administrativas mediante las que se hubieran otorgado o modificado, disociando, en su caso, los datos personales de las personas físicas". BLANES CLIMENT, "La incidencia de la nueva ley...", cit. p. 141. Asimismo, detalla que se pondrán a disposición del público: una copia de la autorización ambiental integrada y de cualesquiera condiciones y actualizaciones posteriores; y una memoria en la que se recojan los principales motivos y consideraciones en los que se basa la resolución administrativa, con indicación de los motivos y las consideraciones de la decisión, incluyendo la información relativa al proceso de participación pública, de acuerdo también con el artículo 23 ap. 2 y 3 de la Ley 16/2002.

91 Esta salvedad no la contempla la Directiva, con lo que podría cuestionarse si realmente no se está recortando la obligación activa de difundir tal información. El hecho de remitirse a las obligaciones generales parece salvaguardar el derecho de acceso a esta información a través de la difusión activa, pero lo que es evidente es que será más difícil acceder a ella.
} 
Administraciones públicas que adopten las medidas adecuadas para identificar a las personas que deban ser consultadas, con el fin de garantizar que su participación en los procedimientos de evaluación ambiental sea efectiva. Además, establece la posibilidad de crear registros para la inscripción de las personas físicas o jurídicas que acrediten la condición de persona interesada de acuerdo con la definición contenida en esa ley ${ }^{92}$.

Por último, la disposición adicional octava de la Ley 27/2006 añade a la lista otra obligación activa en relación con la difusión de la información, a saber, la elaboración y publicación de información periódica de carácter estadístico sobre las solicitudes de información ambientales recibidas, así como de la información sobre la experiencia adquirida en aplicación de esta ley, garantizando en todo caso la confidencialidad de los solicitantes. También añade que para este cometido, así como para el adecuado cumplimiento de las obligaciones internacionales del Estado, las diferentes administraciones públicas colaborarán e intercambiarán la información que resulte necesaria. Estas obligaciones, en definitiva, consisten, en primer lugar, en difundir datos estadísticos sobre, por ejemplo, el número de solicitudes de información y sobre qué materias se ha requerido tal información; en segundo lugar, en dar publicidad a datos estadísticos sobre el ejercicio que se ha hecho del derecho de acceso a la información en aplicación de la Ley y evaluar su aplicación; y, en tercer lugar, la colaboración de las diferentes administraciones públicas para poder recopilar y publicar estos datos, en particular, y poder cumplir las obligaciones generales que la Ley exige ${ }^{93}$.

Con esta legislación vemos que se ha ampliado cuantitativa y cualitativamente la información exigida a las autoridades públicas para su difusión activa. No obstante, la disposición transitoria única dispone que dicha información deberá incluir los datos recogidos desde el 14 de febrero de 2003, mientras que los datos anteriores a dicha fecha solo se incluirán cuando ya existieran en forma electrónica.

La doctrina está de acuerdo en que la aprobación de la Ley 19/2013 comporta una ampliación de la obligación de difusión activa en materia de información ambiental en lo que al ámbito objetivo concierne. Esto es así porque la principal novedad en materia de difusión activa que contiene la Ley de Transparencia es la obligación de las

\footnotetext{
92 Sobre esta ley, véase, entre otros, GARCÍA URETA, A.M., "Comentarios sobre la Ley 21/2013, de evaluación ambiental”, Revista de Administración Pública, núm. 194, 2014, pp. 317-371.

93 En la web del MAGRAMA, como ya hemos señalado con anterioridad, encontramos estos datos estadísticos hasta el año 2013.
} 
administraciones públicas de publicar cierta información de relevancia jurídica que la Ley ambiental no exige. Dado que la Ley 27/2006 no lo exige y esta ley general sí, será de aplicación supletoria en estos términos y, por lo tanto, toda administración pública deberá, en el ámbito de sus competencias, publicar: a) las directrices, instrucciones, acuerdos, circulares o respuestas a consultas planteadas por los particulares u otros órganos en la medida en que supongan una interpretación del derecho o tengan efectos jurídicos; b) los anteproyectos de ley y los proyectos de decretos legislativos cuya iniciativa les corresponda, cuando se soliciten los dictámenes a los órganos consultivos correspondientes; en caso de que no sea preceptivo ningún dictamen, la publicación se realizará en el momento de su aprobación; c) los proyectos de reglamentos cuya iniciativa les corresponda; cuando sea preceptiva la solicitud de dictámenes, la publicación se producirá una vez que estos hayan sido solicitados a los órganos consultivos correspondientes, sin que ello suponga necesariamente la apertura de un trámite de audiencia pública; d) las memorias e informes que conformen los expedientes de elaboración de los textos normativos, en particular la memoria del análisis de impacto normativo regulada por el Real Decreto 1083/2009, de 3 de julio; y e) los documentos que, conforme a la legislación sectorial vigente, deban ser sometidos a un período de información pública durante su tramitación (art. 7) ${ }^{94}$.

Asimismo, cabe recordar que también será de aplicación la obligación de difusión ambiental que prevé el artículo 5.1 de la Ley 19/2013. En el artículo 6 se enuncian otras obligaciones de publicidad activa en relación con tres cuestiones básicas: la normativa que les sea de aplicación; las funciones que desarrollan, su estructura organizativa (art. 6.1); y otras obligaciones que solo vinculan a las administraciones públicas, como los planes y programas anuales, entre otros (art. 6.2). También en el artículo 8, sobre materias relativas a los actos de gestión administrativa con repercusión económica o presupuestaria, se establece la obligación de publicar activamente los contratos y convenios celebrados con la Administración pública y las subvenciones y ayudas

\footnotetext{
${ }^{94}$ RIDAO MARTÍN y LOZANO CUTANDA destacan la obligación de que las administraciones públicas "deban publicar los proyectos normativos con anterioridad a la solicitud de los dictámenes preceptivos, así como las memorias e informes que integren los expedientes de elaboración de textos normativos, y en particular la memoria del análisis del impacto normativo regulada por el Real Decreto 1083/2009, de 3 de julio". RIDAO MARTÍN, J., "Consideraciones ante la futura efectividad de la Ley 19/2013, de 9 de diciembre, de transparencia, acceso a la información pública y buen gobierno", Diario La Ley, núm. 8340, 2014; y LOZANO CUTANDA, Tratado..., cit., p. 287. BLANES CLIMENT comparte nuestra opinión cuando afirma que "como la ley ambiental no lo prevé, sí que resultaría de aplicación lo dispuesto en el artículo 7 de la ley 19/2013", que acabamos de reproducir en el párrafo anterior del texto principal. BLANES CLIMENT, "La incidencia de la nueva ley...", cit., p. 147.
} 
públicas recibidas de ella ${ }^{95}$; en este caso se considerará como publicidad activa de la información pública general, no estrictamente ambiental, y se plasmará en un listado de mínimos.

\section{La difusión de la información en caso de amenaza inminente para la salud humana o el medio ambiente}

El Convenio de Aarhus (art. 5.1), la Directiva 2003/4/CE (art. 7.4) y la legislación estatal (art.9) prevén la difusión inmediata de información en casos excepcionales y de alto riesgo. La Ley estatal prevé que, en caso de amenaza inminente para la salud humana o para el medio ambiente ocasionada por actividades humanas o por causas naturales, las administraciones públicas difundan inmediatamente y sin demora toda la información que obre en su poder o en el de otros sujetos en su nombre, de forma que ello permita al público que pueda resultar afectado adoptar las medidas necesarias para prevenir o limitar los daños que pudieran derivarse de dicha amenaza.

En este caso, los sujetos obligados a difundir la información son exclusivamente las administraciones públicas, que actuarán como centro de recopilación y de difusión de la información que tengan tanto ellas como otros sujetos que la posean en su nombre.

El modo de difundir esta información no se concreta, pero sí el fin: permitir al público que pueda resultar afectado adoptar las medidas necesarias para prevenir o limitar los daños que pudieran derivarse. Según el tipo de amenaza de que se trate, la información irá dirigida a sectores concretos de la sociedad. Por ejemplo, a poblaciones o personas concretas. La Ley prevé expresamente que se diferencie la información por razón de sexo cuando sea un factor significativo para la salud humana. Desconocemos la razón por la que se ha optado por esta diferenciación y no acabamos de entender su importancia, pero sí echamos en falta la posibilidad de haber diferenciado por sectores de riesgo para la salud, por ejemplo, niños, ancianos... ${ }^{96}$.

Cabe apuntar que tal obligación no excluye las obligaciones específicas de informar que se deriven de la legislación vigente, sino que se suma a ella, y, en aquellos casos en que

\footnotetext{
${ }^{95}$ Véase, GUICHOT REINA, Transparencia, ..., cit., 158-193.

${ }^{96}$ RAZQUIN LIZARRA señala que habría sido más adecuado diferenciar no por sexo sino por grupos de riesgo para la salud y pone el ejemplo siguiente: ante un caso de contaminación atmosférica local, es importante que se difunda esta información a los principales grupos de riesgo tales como personas que padecen patologías respiratorias como asma o ancianos; Información..., cit., p. 190.
} 
no exista normativa específica, se deberá difundir dicha información ${ }^{97}$. Por otro lado, se prevén dos supuestos en los que se excluye esta obligación: cuando concurran causas de defensa nacional o de seguridad pública.

\section{Las consecuencias del incumplimiento de las obligaciones de difusión activa de la}

\section{información}

La Ley 27/2006 no establece ninguna previsión relacionada con el incumplimiento de las obligaciones que se exigen. Sin embargo, de acuerdo con el artículo 9, "control", apartado 3, de la Ley 19/2013, "el incumplimiento reiterado de las obligaciones de publicidad activa reguladas en este capítulo tendrá la consideración de infracción grave a los efectos de aplicación a sus responsables del régimen disciplinario previsto en la correspondiente normativa reguladora".

Cabrá ver qué establece la normativa reguladora, suponemos que el reglamento, a tal efecto y qué repercusiones reales tiene dicho incumplimiento. Entendemos que, en la medida en que se refiere a las obligaciones reguladas en este capítulo - es decir, el capítulo II, "publicidad activa"-, solamente se podrá aplicar dicho régimen sancionador a las obligaciones derivadas de este $\mathrm{y}$, en consecuencia, no podrá aplicarse a las obligaciones derivadas de la Ley $27 / 2006$, aunque sí a aquellas que se apliquen en virtud de la Ley 19/2013.

La Ley de Transparencia encomienda esta tarea de control del cumplimiento de las obligaciones asignadas a la Administración general del Estado al Consejo de Transparencia y Buen Gobierno (CTBG), el cual podrá dictar resoluciones en las que se establezcan las medidas que sea necesario adoptar para el cese del incumplimiento y el inicio de las actuaciones disciplinarias que procedan. Será el reglamento el que establezca el procedimiento ${ }^{98}$.

\footnotetext{
${ }^{97}$ Las normativas de protección civil, de emergencias y sanitarias prevén obligaciones específicas en este ámbito.

${ }^{98}$ GUICHOT REINA pone de manifiesto, por una parte, que el artículo 9 no tiene carácter básico, con lo que, sin justificación aparente, se ha desprovisto de carácter básico al mecanismo sancionatorio y dependerá de la normativa autonómica si son sancionables y en qué medida los incumplimientos de las obligaciones de publicidad activa por los sujetos bajo el imperio de dicha normativa. Por otra, también las cuestiones abiertas que suscita, por ejemplo, si un incumplimiento constituye una infracción leve y una reiteración una grave o solo se sancionan las segundas y si al CTBG le corresponde instar el ejercicio de la potestad disciplinaria o ejercerla, entre otras. GICHOT REINA, Transparencia ..., cit., p. 198.
} 


\section{CONCLUSIONES}

El Convenio de Aarhus propició que el Estado español se modernizara y ampliara la esfera del concepto de transparencia en materia de acceso a la información medioambiental en manos de las autoridades públicas. La normativa estatal, con más de diez años de vigencia, ha conllevado una apertura de la Administración pública hacia el ciudadano y un avance en cuanto a la garantía y la posibilidad de mantener informadas a las personas, y ha facilitado el derecho de participación y de acceso a la justicia en esta materia.

A pesar de la discusión doctrinal sobre la consideración de la transparencia como un mero principio o como un derecho fundamental, finalmente el Estado español ha promulgado una normativa general sobre transparencia, acceso a la información pública y buen gobierno, lo que comporta, por lo menos en lo plasmado en el papel, una manifestación más de los valores democráticos. Faltará ver cómo se aplica y se desarrolla efectivamente.

En este estudio se ha pretendido imbricar una y otra normativa en aras de conocer las repercusiones que tiene la promulgación de la Ley 19/2013 sobre la Ley 27/2006, en especial en relación con la difusión o publicidad activa y los sujetos obligados por ambas normativas. En la medida en que la Ley ambiental es una ley especial que regula el acceso a la información ambiental, tal y como hemos analizado, tan solo le será de aplicación la Ley 19/2013 en aquello que no esté previsto en la Ley especial, teniendo así, carácter supletorio. La doctrina no es unánime a la hora de interpretar el alcance de esta normativa en relación con los sujetos obligados por una u otra normativa a difundir o publicitar información. Sin embargo, en nuestra opinión la lista de sujetos obligados se verá ampliada. Por otro lado, en cuanto al modo de difundir la información, ambas normativas coinciden e incluso destacan la necesidad de hacer entendible la información y de disociar los datos protegidos de los relevantes para la información. En cuanto al contenido de la información que deben hacer pública los sujetos obligados, la Ley 19/2013 amplía las exigencias previstas hasta el momento por la Ley 27/2006 en relación con la información de relevancia jurídica a la que obliga el artículo 7 de la Ley 19/2013, en especial en lo que se refiere a los anteproyectos de ley y los proyectos de decretos legislativos, los proyectos de reglamento cuya iniciativa les corresponda y las memorias e informes que conformen los expedientes de elaboración de los textos 
normativos, en particular, la memoria del análisis de impacto normativo regulada por el RD 1083/2009, de 3 de julio, entre otros.

\section{BIBLIOGRAFÍA}

ALENZA GARCÍA, J. F. (dir.), El derecho contra el ruido, Aranzadi, Cizur Menor, 2013.

ALONSO GARCÍA, E. y LOZANO CUTANDA, B., Diccionario de Derecho Ambiental, iustel, Madrid, 2005.

BALLESTEROS MOFFA, L. Á., "La ausencia de respuesta a las solicitudes y reclamaciones de acceso a la información pública: ¿el caballo de Troya de la transparencia?", Revista Española de Derecho Administrativo, núm. 161, 2014, pp. 75100.

— "La inactividad de la Administración frente al "derecho a saber" del ciudadano", Revista Jurídica de Castilla y León, núm. 33, mayo de 2014.

BECK, Ulrich y KROPP, C., "Environmental risk and public perceptions”, Pretty, J. et ál., The SAGE handbook of environmenta and society, SAGE publications Ltd., 2008.

BLANES CLIMENT, M. Á., La transparencia informativa de las Administraciones públicas. El derecho de las personas a saber y la obligación de difundir información pública de forma activa, Aranzadi, Cizur Menor, 2014.

CASADO CASADO, L., "El derecho de acceso a la información ambiental a través de la jurisprudencia”, Revista de Administración Pública, núm. 178, 2009, pp. 281-322.

- "Estudio sobre el alcance de la supletoriedad de la Ley 19/2013, de 9 de diciembre, de transparencia, acceso a la información pública y buen gobierno sobre la Ley 27/2006, de 18 de julio, reguladora del derecho de acceso a la información ambiental", Revista Vasca de Administración Pública, núm. 99-100, 2014, pp. 819-946. COTINO HUESO, L. y VALERO TORRIJOS, J. (coords.), Administración electrónica. La ley 11/2007, de 22 de junio, de acceso electrónico de los ciudadanos a los Servicios Públicos y los retos jurídicos del e-gobierno en España, Tirant lo Blanch, Valencia, 2010. 
ESTEVE PARDO, José, "Derecho y medio ambiente: problemas generales: El Derecho del medio ambiente como Derecho de decisión y gestión de riesgos", Revista electrónica del Departamento de Derecho de la Universidad de La Rioja, REDUR, núm. 4, 2006.

EZEIZABARRENA SÁENZ, X., "Participación y acceso a la justicia ambiental: el convenio de Aarhus de 1998", Revista Aranzadi de Derecho Ambiental, núm. 1, 2002, pp. 245-251.

FERNÁNDEZ RAMOS, S., El derecho de acceso a la información ambiental, Thomson Aranzadi, Cizur Menor, 2009.

- $\quad$ "El acceso a la información en el proyecto de ley de transparencia, acceso a la información pública y buen gobierno", Monografias de la Revista Aragonesa de Administración Pública, XIV, Zaragoza, 2013, pp. 233-298.

GARCÍA MACHO, R. (ed.), Derecho administrativo de la información y administración transparente, Marcial Pons, Madrid, 2010.

- "El derecho a la información, la publicidad y transparencia en las relaciones entre la administración, el ciudadano y el público”, García Macho, R. (ed.), Derecho administrativo de la información y administración transparente, Marcial Pons, Madrid, 2010 .

GARCÍA URETA, A., "Algunas cuestiones sobre la regulación del derecho de participación a la luz del Convenio de Aarhus de 1998", Revista Aranzadi de Derecho Ambiental, núm. 7, 2005, pp. 43-70.

- "Perspectivas sobre el derecho de acceso a la información sobre el ambiente: un repaso a la Directiva 90/313/CEE, Revista de Derecho Ambiental, núm. 13, 1994, pp. 119-164.

- "Comentarios sobre la Ley 21/2013, de evaluación ambiental", Revista de Administración Pública, núm. 194, 2014, pp. 317-371.

GUICHOT REINA, E. (coord.), Transparencia, acceso a la información pública y buen gobierno. Estudio de la Ley 19/2013, de 9 de diciembre, Tecnos, Madrid, 2014.

JIMÉNEZ PLAZA, M. I., El Derecho de acceso a la información municipal, iustel, Madrid, 2006. 
LOZANO CUTANDA, B. (dir.), Comentario a la ley del ruido, ley 37/2003, de 17 de noviembre, Civitas, Madrid, 2004.

- Administración y legislación ambiental, Dykinson, Madrid, 2005.

- Derecho Ambiental Administrativo, Dykinson, Madrid, 2007

- Tratado de Derecho Ambiental, CEF, Madrid, 2014.

MESTRE DELGADO, J. F., El derecho de acceso a archivos y registros administrativos (Análisis del artículo 105.b) de la Constitución), Civitas, Madrid, 1993.

OLLE RUBERT, M., "Comentario a la sentencia del tribunal de justicia de la Unión Europea de 14 de febrero de 2012: el derecho de acceso a la información en materia de medio ambiente y sus restricciones”, Revista Aranzadi de Derecho Ambiental, núm. 24, 2013, pp. 171-180.

PIGRAU SOLÉ, A. (coord.), Acceso a la información, participación pública y acceso a la justicia en materia de medio ambiente: diez años del Convenio de Aarhus, Atelier, Barcelona, 2008.

PIÑAR MAÑAS, J. L., “Transparencia y protección de datos. Una referencia a la Ley 19/2013, de 9 de diciembre, de transparencia, acceso a la información y buen gobierno", Piñar Mañas, J. L. (dir.), Transparencia, acceso a la información y protección de datos, ed. Reus, Madrid, 2014.

PLAZA MARTíN, C., Derecho Ambiental de la Unión Europea, ed. Tirant lo Blanch, Valencia, 2005.

RAZQUIN LIZARRAGA, J. A. y RUIZ DE APODACA ESPINOSA, A., Información, participación y justicia en materia de medio ambiente, comentario sistemático a la Ley 27/2006, de 18 de julio, Thomson Aranzadi, Navarra, 2007.

RIDAO MARTÍN, J., “Consideraciones ante la futura efectividad de la Ley 19/2013, de 9 de diciembre, de transparencia, acceso a la información pública y buen gobierno", Diario La Ley, núm. 8.340, 2014.

SALAZAR ORTUÑO, E., "El desarrollo del Convenio de Aarhus y la progresiva desaparición de obstáculos para el acceso a la justicia ambiental: reconocimiento en la jurisprudencia del Tribunal Supremo de la legitimación activa a las organizaciones no gubernamentales que trabajan a favor de la protección del ambiente", Revista Aranzadi de Derecho Ambiental, núm. 17, 2010, pp. 191-202. 
- "Implicaciones del Convenio de Aarhus en la legislación sobre acceso a la justicia de los Estados: la Sentencia Trianel del Tribunal de Justicia de la Unión Europea de 12 de mayo de 2011, C-115/09”, Revista Aranzadi de Derecho Ambiental, núm. 23, 2012, pp. 413-432.

SÁNCHEZ MORÓN, M., Derecho Administrativo, parte general, 10. a edición, Tecnos, Madrid, 2014.

SOMMERMANN, K.P., "La exigencia de una Administración transparente en la perspectiva de los principios de democracia del Estado de derecho”, García Macho, R. (ed.), Derecho administrativo de la información y administración transparente, Marcial Pons, Madrid, 2010. 